\title{
European Society of Endocrinology Clinical Guideline: Treatment of chronic hypoparathyroidism in adults
}

\author{
Jens Bollerslev ${ }^{1,2, *}$, Lars Rejnmark ${ }^{3, *}$, Claudio Marcocci ${ }^{4}$, Dolores M Shoback ${ }^{5}$, \\ Antonio Sitges-Serra ${ }^{6}$, Wim van Biesen ${ }^{7}$ and Olaf M Dekkers ${ }^{8,9,10}$ \\ ${ }^{1}$ Section of Specialized Endocrinology, Clinic of Medicine, Oslo University Hospital, Oslo, Norway, ${ }^{2}$ Faculty of \\ Medicine, University of Oslo, Oslo, Norway, ${ }^{3}$ Department of Endocrinology and Internal Medicine, Aarhus \\ University Hospital, Aarhus, Denmark, ${ }^{4}$ Department of Clinical and Experimental Medicine, University of Pisa, Pisa, \\ Italy, ${ }^{5}$ Endocrine Research Unit, Department of Veterans Affairs, San Francisco VA Medical Center, University of \\ California, San Francisco, California, USA, ${ }^{6}$ Endocrine Surgery Unit, Hospital Universitari del Mar, Barcelona, Spain, \\ ${ }^{7}$ Renal Division, Ghent University Hospital, Ghent, Belgium, ${ }^{8}$ Division of Endocrinology, Department of Medicine \\ and ${ }^{9}$ Department of Clinical Epidemiology, Leiden University Medical Center, Leiden, The Netherlands and \\ ${ }^{10}$ Department of Clinical Epidemiology, Aarhus University Hospital, Aarhus, Denmark \\ *(J Bollerslev and L Rejnmark share first authorship)
}

Correspondence should be addressed to J Bollerslev Email Jens.bollerslev@ medisin.uio.no

\begin{abstract}
Hypoparathyroidism (HypoPT) is a rare (orphan) endocrine disease with low calcium and inappropriately low (insufficient) circulating parathyroid hormone levels, most often in adults secondary to thyroid surgery. Standard treatment is activated vitamin $\mathrm{D}$ analogues and calcium supplementation and not replacement of the lacking hormone, as in other hormonal deficiency states. The purpose of this guideline is to provide clinicians with guidance on the treatment and monitoring of chronic HypoPT in adults who do not have end-stage renal disease. We intend to draft a practical guideline, focusing on operationalized recommendations deemed to be useful in the daily management of patients. This guideline was developed and solely sponsored by The European Society of Endocrinology, supported by CBO (Dutch Institute for Health Care Improvement) and based on the Grading of Recommendations Assessment, Development and Evaluation (GRADE) principles as a methodological base. The clinical question on which the systematic literature search was based and for which available evidence was synthesized was: what is the best treatment for adult patients with chronic HypoPT? This systematic search found 1100 articles, which was reduced to 312 based on title and abstract. The working group assessed these for eligibility in more detail, and 32 full-text articles were assessed. For the final recommendations, other literature was also taken into account. Little evidence is available on how best to treat HypoPT. Data on quality of life and the risk of complications have just started to emerge, and clinical trials on how to optimize therapy are essentially non-existent. Most studies are of limited sample size, hampering firm conclusions. No studies are available relating target calcium levels with clinically relevant endpoints. Hence it is not possible to formulate recommendations based on strict evidence. This guideline is therefore mainly based on how patients are managed in clinical practice, as reported in small case series and based on the experiences of the authors.
\end{abstract}

\section{Summary of recommendations}

The recommendations are worded as recommend (strong recommendation) and suggest (weak recommendation). We formally graded only the evidence underlying recommendations for therapeutic choices and target calcium (c) 2015 European Society of Endocrinology Printed in Great Britain levels. The quality of evidence behind the recommendations is classified as very low $(\oplus \bigcirc \bigcirc \bigcirc)$, low $(\oplus \oplus \bigcirc \bigcirc)$, moderate $(\oplus \oplus \oplus \bigcirc)$ and strong $(\oplus \oplus \oplus \oplus)$. See further section 'Summary of methods used for guideline development'.

Published by Bioscientifica Ltd. 


\subsection{Diagnosis}

R.1.1 We recommend considering a diagnosis of chronic hypoparathyroidism (HypoPT) in a patient with hypocalcaemia and inappropriately low parathyroid hormone (PTH) levels.

R.1.2 We suggest considering genetic testing and/or family screening in a patient with HypoPT of unknown aetiology.

\subsection{General goals of management in chronic HypoPT}

R.2.1 We suggest treatment targeted to maintain serum calcium level (albumin adjusted total calcium or ionized calcium) in the lower part or slightly below the lower limit of the reference range (target range) with patients being free of symptoms or signs of hypocalcaemia. $(\oplus \bigcirc \bigcirc \bigcirc)$ R.2.2 We suggest that 24-h urinary calcium excretion should be within the sex-specific reference range. $(\oplus \bigcirc \bigcirc \bigcirc)$ R.2.3 We suggest that serum phosphate levels should be within the reference range. $(\oplus \bigcirc \bigcirc \bigcirc)$

R.2.4 We suggest that the serum calcium-phosphate product should be below $4.4 \mathrm{mmol}^{2} / \mathrm{l}^{2}\left(55 \mathrm{mg}^{2} / \mathrm{dl}^{2}\right)$. $(\oplus \bigcirc \bigcirc \bigcirc)$

R.2.5 We suggest that serum magnesium levels should be within the reference range. $(\oplus \bigcirc \bigcirc \bigcirc)$

R.2.6 We suggest aiming at an adequate vitamin D status. $(\oplus \bigcirc \bigcirc \bigcirc)$

R.2.7 We recommend that treatment be personalized and focused on the overall well-being and quality of life (QoL) of the patient when implementing different therapeutic efforts, aiming to achieve the therapeutic goals.

R.2.8 We recommend providing information/education that enables patients to know the possible symptoms of hypo- or hypercalcaemia and/or complications of their disease.

\subsection{Treatment}

R.3.1 We recommend treatment of all patients with chronic HypoPT with symptoms of hypocalcaemia and/or an albumin adjusted serum calcium level $<2.0 \mathrm{mmol} / \mathrm{l}\left(<8.0 \mathrm{mg} / \mathrm{dl} /\right.$ ionized serum calcium $\left(\mathrm{S}-\mathrm{Ca}^{2+}\right)$ levels $<1.00 \mathrm{mmol} / \mathrm{l})$. $(\oplus \bigcirc \bigcirc \bigcirc)$

R.3.2 We suggest offering treatment to asymptomatic patients with chronic HypoPT and an albumin adjusted calcium level between $2.0 \mathrm{mmol} / \mathrm{l}\left(8.0 \mathrm{mg} / \mathrm{dl} / \mathrm{S}-\mathrm{Ca}^{2+} 1.00 \mathrm{mmol} / \mathrm{l}\right)$ and the lower limit of the reference range in order to assess whether this may improve their well-being. $(\oplus \bigcirc \bigcirc \bigcirc)$

R.3.3 We recommend the use of activated vitamin D analogues plus calcium supplements in divided doses as the primary therapy. $(\oplus \bigcirc \bigcirc \bigcirc)$
R.3.4 If activated vitamin D analogues are not available, we recommend treatment with calciferol (preferentially cholecalciferol).

R.3.5 We recommend that the doses of activated vitamin D analogues or cholecalciferol are titrated in such a manner that patients are without symptoms of hypocalcaemia and serum calcium levels are maintained within the target range. $(\oplus \bigcirc \bigcirc \bigcirc)$

R.3.6 We recommend vitamin D supplementations in a daily dose of 400-800 IU to patients treated with activated vitamin $\mathrm{D}$ analogues. $(\oplus \bigcirc \bigcirc \bigcirc)$

R.3.7 In a patient with hypercalciuria, we suggest considering a reduction in calcium intake, a sodium-restricted diet, and/or treatment with a thiazide diuretic. $(\oplus \bigcirc \bigcirc \bigcirc)$

R.3.8 In a patient with renal stones, we recommend evaluation of renal stone risk factors and management according to relevant international guidelines.

R.3.9 In a patient with hyperphosphataemia and/or an elevated calcium-phosphate product, we suggest considering dietary interventions and/or adjustment of treatment with calcium and vitamin $\mathrm{D}$ analogues.

R.3.10 In a patient with hypomagnesaemia, we suggest considering measures that may increase serum magnesium levels.

R.3.11 We recommend against the routine use of replacement therapy with PTH or PTH analogues. $(\oplus \bigcirc \bigcirc \bigcirc)$

\subsection{Monitoring}

R.4.1 We recommend routine biochemical monitoring of serum levels ionized or albumin adjusted total calcium, phosphate, magnesium and creatinine (estimated glomerular filtration rate (eGFR)), as well as assessment of symptoms of hypocalcaemia and hypercalcaemia at regular time intervals (e.g. every 3-6 months).

R.4.2 Following changes in therapy, we recommend biochemical monitoring weekly or every other week.

R.4.3 We suggest considering monitoring of 24-h urinary calcium excretion at regular, but longer time intervals (e.g. once a year or every second year).

R.4.4 We recommend renal imaging if a patient has symptoms of renal stone disease or if serum creatinine levels start to rise.

R.4.5 We suggest monitoring for development of signs or symptoms of co-morbidities at regular time intervals (e.g. yearly).

R.4.6 We advise against routine monitoring of bone mineral density (BMD) by dual energy X-ray absorptiometry (DXA) scans. 


\subsection{Special circumstances}

\section{Autosomal dominant hypocalcaemia}

R.5.1 We recommend frequent monitoring of patients with autosomal dominant hypocalcaemia (ADH), who are being treated with calcium and/or activated vitamin D analogues, as such patients may be at high risk of hypercalciuria and renal complications.

\section{Pregnancy and breastfeeding}

R.5.2 We suggest treatment with activated vitamin D analogues and calcium supplements as in non-pregnant women.

R.5.3 We suggest monitoring serum ionized calcium regularly (every 2nd or 3rd week) during pregnancy and breastfeeding with levels to be kept at the lower end of the normal range (serum albumin adjusted total calcium is also acceptable).

R.5.4 We recommend that the pediatrician and/or neonatologist be informed of maternal HypoPT, and be involved in the immediate care and monitoring of the infant for possible consequences of the treatment of the mother and the underlying maternal disorder.

\section{Clinical considerations in chronic HypoPT}

\subsection{Aetiology and epidemiology}

HypoPT is an endocrine disease with low calcium and inappropriately low (insufficient) circulating PTH levels $(1,2,3,4)$. It is a rare condition, designated as an orphan disease by the European Commission in January 2014 (EU/3/13/1210) (http://www.ema.europa.eu/ema/index. jsp?curl = pages/medicines/human/orphans $/ 2014 / 01 /$ human_orphan_001301.jsp\&mid=WC0b01ac058001 $\mathrm{d} 12 \mathrm{~b}$ ) and the only major endocrine condition today, where the hormonal insufficiency in general is not treated by substitution of the missing hormone (PTH). The most common cause of chronic HypoPT is neck surgery, i.e. secondary to thyroid or parathyroid surgery (5). HypoPT may have an autoimmune pathogenesis (6), and in many such patients, the cause is a mutation in the autoimmune regulator of endocrine function (AIRE) gene. In addition, there are many other rare genetic conditions that can cause HypoPT either as part of a syndrome (e.g. DiGeorge syndrome (7)) or as an isolated endocrinopathy (see Table 1). In addition to genetic testing for AIRE mutations, one can consider genetic testing for the DiGeorge syndrome or for mutations in the calciumsensing receptor (CASR), PTH, GATA3, GCM2, GNA11 and
Table 1 Genetic etiologies of hypoparathyroidism (HypoPT).

Isolated HypoPT due to mutations in

GCM2

PTH

CASR

GNA11

Syndromes of HypoPT due to mutations or deletions in

Autoimmune polyendocrine syndrome type $1-A I R E$

DiGeorge syndrome - chromosome $22 \mathrm{q}$

Sanjad-Sakati/Kenny-Caffey type 1 - TBCE

Kenny-Caffey type 2 - FAM111A

Mitochondrial DNA

GCM2, glial cell missing 2; PTH, parathyroid hormone; $C A S R$, extracellular calcium-sensing receptor; GNA11, G-alpha 11; $A I R E$, autoimmune regulator of endocrine function; $T B C E$, tubulin-specific chaperone $\mathrm{E} ;$ FAM111A, family with sequence similarity 111 , member $A$.

other genes noted in Table 1 under the appropriate clinical circumstances. Young patients with non-surgical HypoPT may be considered for such testing.

The prevalence of HypoPT has recently been systematically studied in Denmark, where a total of more than 2000 patients were identified giving a prevalence of 24/100 000 inhabitants, among whom only a minority $(2 / 100000)$ had HypoPT due to non-surgical causes $(8,9)$. These estimates are in agreement with recent data from the USA, showing a prevalence of the same magnitude for patients with chronic HypoPT (10).

\subsection{Postsurgical HypoPT}

Chronic HypoPT in adults of more than 6 months duration is usually secondary to previous thyroid surgery but may also occur following parathyroidectomy or other cervical surgical procedures. Completion thyroidectomy (after previous partial thyroidectomy) or lymph node dissection of the central neck compartment for locally recurrent cancer may also lead to HypoPT. Overall, between 2 and $10 \%$ of patients submitted to total thyroidectomy (often associated with central/lateral lymph node dissection in cases of thyroid cancer) would develop chronic HypoPT (11).

The initial manifestation of postoperative parathyroid failure is hypocalcaemia detected within $24 \mathrm{~h}$ of thyroidectomy, which occurs in 30-60\% of patients undergoing total thyroidectomy. Predisposing factors involved are young age, female gender, Graves' disease, lymphadenectomy, accidental parathyroidectomy (including biopsies during surgery for hyperparathyroidism), parathyroid auto-transplantation and, most importantly, the number of functioning parathyroid glands remaining in situ 
$(12,13)$. All these factors contribute to reduced PTH secretion immediately after surgery resulting in hypocalcaemia $(14,15)$. If hypercalcaemia was present prior to surgery (e.g. in a patient with hyperparathyroidism), it may take a few days before serum calcium levels have normalized, during which PTH levels may be very low.

About $60-70 \%$ of cases of postoperative hypocalcaemia resolve within 4-6 weeks after surgery (transient HypoPT). The rest will progress to protracted HypoPT characterized by low serum PTH levels and the need for continued treatment. The most relevant factor leading to protracted HypoPT is the number of functioning parathyroid glands remaining in situ; clinical and diseaserelated variables lose significance at this stage (16).

Finally, about $15-25 \%$ of patients with protracted HypoPT will develop chronic HypoPT. The significant variables favouring recovery from protracted HypoPT are the number of parathyroid glands remaining in situ and the serum calcium level at this stage. Normal to high calcium levels at 1 month after thyroidectomy appears to increase the chance of parathyroid gland recovery. The clinical and disease-related variables do not seem to influence parathyroid function recovery. The risk of chronic HypoPT is closely related to the number of parathyroid glands remaining in situ at operation: $16 \%$ for cases with one to two preserved glands, $6 \%$ for three glands and $2.5 \%$ for four glands (16).

\subsection{Complications and renal implications of chronic HypoPT in adults}

Patients with chronic HypoPT seem to have lower QoL, muscle complaints, including fatigue and weakness, more anxiety and tendency to depression $(17,18,19,20)$. In support of these issues, large cohort studies from Denmark have shown increased risk of hospitalization for depression and affective disorders, renal impairment and infections, whereas the risk for cancer and overall mortality was not increased $(8,21)$. Risks of ischemic heart disease and of cataract are increased in non-surgical HypoPT, but not among patients with postsurgical HypoPT $(8,9,21)$.

HypoPT has traditionally been associated with calcium-containing urolithiasis and renal impairment because of an increased calcium-phosphate product. Loss of renal PTH action decreases renal tubular reabsorption of calcium and excretion of phosphate causing hypercalciuria and hyperphosphataemia respectively (4). Thus, patients with chronic HypoPT have been found to have an increased risk of renal complications, such as renal stones, renal insufficiency and a higher risk for needing dialysis (8). Impaired renal function has been associated with the age of the patient, duration of the disease and relative time with hypercalcaemia (22). In agreement, two smaller cross-sectional studies in patients with mainly postsurgical HypoPT have found renal complication rates in the same magnitude $(17,23)$. Moreover, two-thirds of subjects included in an early intervention trial had decreased creatinine clearance values at baseline, and $40 \%$ had verified renal calcinosis (24). However, despite keen interest in improving the management of HypoPT, large cohort studies describing typical treatment patterns, optimized target laboratory parameters and rates of complications are scarce.

\subsection{Pregnancy and breastfeeding}

Pregnancy and lactation pose substantial short-term challenges to maternal calcium homeostasis, due to the need to mineralize the foetal skeleton and to provide this essential mineral to the breast milk to sustain postnatal skeletal development and well-being in the newborn (25, $26,27,28,29)$. These challenges to the mother are met by vigorous placental production of 1,25-dihydroxyvitamin $\mathrm{D}\left(1,25(\mathrm{OH})_{2} \mathrm{D}\right)$, which stimulates intestinal calcium and phosphate absorption during pregnancy, resulting in higher levels of urinary calcium and low to suppressed endogenous PTH secretion. As pregnancy progresses, PTHrelated protein (PTHrP) production increases in many tissues. PTHrP synthesis rises even further during nursing because it is abundantly produced in lactating mammary tissue. PTHrP increases bone resorption substantially and renal calcium reabsorption, which together provides a steady supply of calcium for milk production. PTHrP's effects on the kidney prompt urinary calcium levels to fall during lactation. Because of the changes in PTHrP and $1,25(\mathrm{OH})_{2} \mathrm{D}$ during pregnancy and lactation, levels of endogenous PTH are suppressed. Although PTH plays a negligible role in regulating calcium homeostasis in pregnancy and lactation in normal women, those with chronic HypoPT, whose serum calcium levels are being maintained by supplemental calcium intake and therapy with vitamin D metabolites or analogues, are at considerable risk for both hypercalcaemia and hypocalcaemia when pregnant or nursing. Poor control of maternal HypoPT and resulting hypocalcaemia during pregnancy can cause miscarriage, stillbirth, premature labour and even neonatal death $(29,30,31,32)$. Maternal hypocalcaemia can affect neonatal skeletal development and cause compensatory hyperparathyroidism in the newborn. Skeletal deformities, fractures, parathyroid hyperplasia 
and clinical complications (e.g. respiratory distress, poor feeding and hypotonia) may result $(27,29,30,31,32,33$, $34,35,36)$. Conversely, maternal overtreatment resulting in hypercalcaemia can suppress foetal parathyroid development causing neonatal hypocalcaemia. To avoid these potential complications, pregnant and nursing women with HypoPT need careful monitoring and medication adjustment by their physicians. The clinical literature on which this summary is based is detailed in Supplemental File III, see section on supplementary data given at the end of this article.

\subsection{Conventional treatment}

The aim of treatment of chronic HypoPT is to relieve symptoms of hypocalcaemia and improve the patient's QoL $(4,37)$. The treatment should aim to maintain serum calcium levels in the low normal range, serum phosphate within the normal range, total calcium-phosphate product below $4.4 \mathrm{mmol}^{2} / \mathrm{l}^{2}\left(55 \mathrm{mg}^{2} / \mathrm{dl}^{2}\right)$, and to avoid hypercalciuria.

Standard treatment includes oral calcium salts and active vitamin D metabolites (Table 2). Hyperphosphataemia should be addressed by decreasing dietary phosphate intake and by eventually increasing calcium supplements, as calcium also acts as a phosphate binder $(4,37,38)$. In the event of hypercalciuria, a thiazide diuretic accompanied by a low salt diet may be advised (39).

Patients with mild hypocalcaemia should be given oral therapy even if they have only nonspecific symptoms (fatigue, brain fog and anxiety), since they may improve with treatment. Dietary calcium intake should be optimized, according to the guidelines for the general population $(40,41)$. Magnesium-depleted patients should be replete with this mineral.

In cases of symptomatic severe hypocalcaemia, the use of i.v. calcium should be considered for a limited period of time. Serum calcium and phosphate should be monitored weekly or twice weekly during the initial dose adjustment period and every 3rd-6th month when serum levels are stable. Also suggested are 24-h urinary calcium excretion to be measured yearly or every other year.

\subsection{PTH replacement therapy}

Replacement therapy with recombinant human PTH (rhPTH) in terms of either the N-terminal fragment (rhPTH(1-34)) or intact PTH (rhPTH(1-84)) seems to be an attractive option for those patients who do not stably and safely maintain their serum and urinary calcium in the target range.

In recent years, a number of studies have been published showing that normocalcaemia can be maintained in response to therapy with $\operatorname{rhPTH}(38,42)$. In most of the studies, PTH has been administered in an unphysiologic manner (once-daily injection), compared to its continuous episodic endogenous pattern of secretion. Owing to the short plasma half-life of PTH, once-daily injections do not cause sustained increased PTH levels. Studies on injections twice-a-day have only been performed on $\operatorname{rhPTH}(1-34)$, showing less fluctuations in serum calcium levels compared with injections once-a-day (43). However, compared with conventional therapy, injection therapy with rhPTH has so far not been documented to cause a significant reduction in 24-h urinary calcium, to improve QoL or to lower risk of complication related to HypoPT. Recently, a National Institutes of Health (NIH) sponsored study in the USA showed an almost normalization of the diurnal rhythm of PTH, calcium and phosphate levels in response to rhPTH(1-34) therapy delivered by an (insulin) infusion pump (44). Pump delivery also lowered $24 \mathrm{~h}$ urinary calcium significantly compared with twice-a-day injection therapy with rhPTH(1-34). So far, no data are available on whether continuous infusions of rhPTH will improve QoL and reduce the risk of complications.

In January 2015, the American Food and Drug Administration approved the use of $\mathrm{rhPTH}(1-84)$ (Natpara) as a supplement to conventional treatment (FDA

Table 2 Vitamin D metabolites in the management of chronic hypoparathyroidism ${ }^{\text {a }}$.

\begin{tabular}{|c|c|}
\hline Medication & Typical dose \\
\hline Calcitriol $\left(1,25(\mathrm{OH})_{2} \mathrm{D}_{3}\right)$ & $0.25-2.0 \mu \mathrm{g}$ once or twice daily \\
\hline Alfacalcidiol $^{\mathrm{b}}\left(1 \alpha(\mathrm{OH}) \mathrm{D}_{3}\right)$ & $0.5-4 \mu \mathrm{g}$ once daily \\
\hline Dihydrotachysterol $^{\mathrm{b}}$ & $0.3-1.0 \mathrm{mg}$ once daily \\
\hline $\begin{array}{l}\text { Vitamin } D_{2} \text { (ergocalciferol) or } \\
\text { vitamin } D_{3} \text { (cholecalciferol) }^{c}\end{array}$ & 25 000-200 000 IU daily \\
\hline
\end{tabular}

\begin{tabular}{c} 
Time to onset of action (days) \\
\hline $1-2$ \\
$1-2$ \\
$4-7$ \\
$10-14$
\end{tabular}

\begin{tabular}{c}
\hline Time to offset of action (days) \\
\hline $2-3$ \\
$5-7$ \\
$7-21$ \\
$14-75$
\end{tabular}

aDerived from Shoback (4)

${ }^{b}$ Alfacalcidiol and dihydrotachysterol are rapidly activated in the liver to $1,25(\mathrm{OH})_{2} \mathrm{D}$ and $25(\mathrm{OH})$ dihydrotachysterol.

'These compounds could be used in a setting where active vitamin D metabolites are not available and/or too expensive. 
2015: http://www.fda.gov/NewsEvents/Newsroom/PressAnnouncements/ucm431358.htm). The drug is only available through a restricted program under a Risk Evaluation and Mitigation Strategy (REMS) and carries a 'black box warning' that bone cancer (osteosarcoma) has been observed in rat studies with rhPTH. It is unknown whether long-term therapy also may cause osteosarcoma in humans, but because of a potential risk rhPTH(1-84) is only recommended for use in patients whose hypocalcemia cannot be controlled on calcium supplementation and active forms of vitamin D, and for whom the potential benefits are considered to outweigh this potential risk. The drug is supposed to be administered as a once-a-day s.c. injection in the thigh with a starting dose of $50 \mu \mathrm{g}$. At the time of initiation of therapy, daily dose of active vitamin $\mathrm{D}$ is reduced by $50 \%$, and serum calcium levels are monitored once- or twice-a-week. According to a predefined schedule, daily dose of active vitamin $\mathrm{D}$ and calcium supplements may be further reduced according to serum calcium measurement. The dose of $\operatorname{rhPTH}(1-84)$ can be down-titrated to a daily dose of $25 \mu \mathrm{g}$ or up-titrated to a daily injection of either 75 or $100 \mu \mathrm{g}$.

At the time of writing, this ESE guideline on treatment of chronic HypoPT in adults, $\operatorname{rhPTH}(1-84)$ is being evaluated by the European Medicines Agency. If approved for treatment of HypoPT in Europe, it is likely that the indications and usage, similar to USA recommendations, will be restricted to those patients who are difficult to manage on conventional therapy.

\section{Methods}

\subsection{Guideline working group}

This guideline was developed and solely sponsored by The European Society of Endocrinology (ESE), supported by CBO (Dutch Institute for health care improvement). The chairs of the working group $\mathrm{J}$ Bollerslev (clinical) and $\mathrm{O} \mathrm{M}$ Dekkers (methodology) were appointed by the ESE Clinical Committee. The other members: C Marcocci, L Rejnmark and D M Shoback (endocrinologists), W van Biesen (nephrologist) and A Sitges-Serra (endocrine surgeon) were all approved by the Committee. The working group had two in-person meetings (January and December 2014) and communicated by phone and email. Consensus was reached upon discussion; minority positions were taken into account in the rationale behind recommendations. Prior to the process, all participants completed conflict of interest forms.

\subsection{Target group}

This guideline was developed for European-based healthcare providers of adult patients with chronic HypoPT, i.e. primarily endocrinologists and specialists in internal medicine. However, general practitioners with a special interest in calcium metabolism might also find the guideline useful, as might our patients. Patient leaflets were developed in collaboration with patients and patient associations (Hypopara UK (www.hypopara.org.uk); The German Working group for HypoPT (www.sd-krebs.de/ ag-hypopara); The US Hypoparathyroidism Association (www.hypopara.org) and the Nordic hypoPARA Organisation (www.hpth.no)) based on the guideline recommendations. A draft of the guideline was reviewed by an expert in the field (see 'Acknowledgements' section), before submitted for external review and comments by ESEmembers, and was presented and discussed at the European Congress of Endocrinology, 18th May 2015 in Dublin.

\subsection{Aims}

The overall purpose of this guideline is to provide clinicians with guidance on the treatment of chronic HypoPT. We intended to draft a practical clinical guideline, focusing on operationalized recommendations that are supposed to be useful in the daily management of adult patients with chronic HypoPT.

\subsection{Summary of methods used for guideline development}

The current guideline has the Grading of Recommendations Assessment, Development and Evaluation (GRADE) principles as methodological base. GRADE is a systematic approach for synthesizing evidence and grading of recommendations (45). The main advantage of the system is the aim for transparency at all stages of the guideline development process. This to provide the reader with all information required to understand the underlying rationale of the provided recommendations.

The first methodological step for the guideline development group is to define the clinical question(s) to be addressed in the guideline (see section 'Clinical question, eligibility criteria and endpoint definition'). These clinical questions are formulated in such ways that their answers can directly inform management decisions. An answer to the question, what is the best treatment in HypoPT to prevent renal complications?, can inform treatment decisions. Whereas the question, is hydrochlorothiazide better than PTH for treatment in HypoPT to prevent renal 
complications?, is too restricted if other alternatives are available but not considered. Importantly, the clinical questions should be specific in terms of populations. For this guideline: chronic HypoPT in adults who do not have end-stage renal disease. Prior to synthesizing and rating available evidence, the guideline development group rated clinical outcomes either as critical, important but noncritical, and not important (46), see section 'Clinical question, eligibility criteria and endpoint definition'.

The clinical questions subsequently formed the base for a systematic literature search (see section 'Description of search and selection of literature'). After including all relevant articles, synthesis of the evidence was made in two directions: i) estimation of an average effect for specific outcomes (if possible) and ii) rating the quality of the evidence. The quality rating is standardized (47) and is provided as a summary rating (using four categories: high, moderate, low and very low) across studies for each outcome, as it may be that quality differs for different outcomes. Evidence tables are provided in Supplemental File II, see section on supplementary data given at the end of this article. Evidence synthesis and quality rating were performed by the guideline methodologist.

For the final recommendations, three elements were taken into account: i) quality of the evidence, ii) balance of desirable and undesirable outcomes and iii) values and preferences (patient preferences, goals for health, costs, management inconvenience, feasibility of implementation, etc.) (48). The recommendations are worded as recommend (strong recommendation) and suggest (weak recommendation). The meaning of a strong recommendation can be stated as follows: reasonably informed persons (clinicians, politicians and patients) would want the management in accordance with the recommendation. For a weak recommendation, most persons would still act in accordance with the guideline, but a substantial number would not (48). Only for recommendations regarding treatment, did we aim for formal evidence synthesis. This was not the case for recommendations on diagnosis, monitoring and special circumstances. Also, recommendations based on good practice were not graded (49). We formally graded the evidence underlying recommendations for therapeutic choices and target calcium levels. The quality of evidence behind the recommendations is classified as very low $(\oplus \bigcirc \bigcirc \bigcirc)$, low $(\oplus \oplus \bigcirc \bigcirc)$, moderate $(\oplus \oplus \oplus \bigcirc)$ and strong $(\oplus \oplus \oplus \oplus)$.

Importantly, there is no automatic step from evidence to recommendations. Often available evidence is of poor quality hampering strong recommendations, but even high quality evidence may not directly translate into a strong recommendation if, for example, the outcome under study is judged as not important or if a management strategy cannot be implemented on a large scale. This highlights the fact that standardized quality judgement still does not eliminate the need for clinical judgement (45). Another consideration is that you cannot abstain from recommendations when there is no evidence, as treatment decisions need to be made any way. For the ESE guidelines, recommendations are achieved by majority reports of the guideline development committee, but if members have substantive disagreements, this will be acknowledged in the manuscript. To optimize transparency, all recommendations provided are accompanied by text explaining why specific recommendations were made.

\subsection{Clinical question, eligibility criteria and endpoint definition}

The clinical question on which the literature search was based and for which available evidence was synthesized was: what is the best treatment for adult patients with chronic HypoPT?

Exclusion criteria for the studies considered were:

i) Patients with HypoPT for $<6$ months.

ii) Intervention $<4$ weeks duration.

iii) Age $<18$ years

iv) Case series.

v) End-stage renal disease.

The following outcomes were rated by the guideline working group as critical:

i) Mortality.

ii) QoL.

iii) Calcium levels in serum or plasma and urine, including incidence of hypercalcaemia.

iv) Chronic kidney disease and renal calcifications defined as symptoms or episodes of nephrolithiasis or nephrocalcinosis.

v) Cramps, tetany and seizures.

vi) Cardiovascular disease defined as the incidence of major adverse cardiovascular events.

vii) Disability or sick leave.

\subsection{Description of search and selection of literature}

A systematic search was done using the database Ovid MEDLINE to find literature from 1970 onward. Systematic reviews, randomized controlled trials (RCTs), cohort studies and case-control studies were eligible. Only articles in Dutch, English, German and French were 
considered. Articles were searched that included adult, human patients with chronic HypoPT ( $>6$ months) as well as the relevant interventions and outcome measures. Only interventions with duration $>4$ weeks were considered. Articles identified by the working group as relevant were used to optimize the search strategy. Articles found by 'snowballing' were also considered.

This systematic search found 1100 articles, reduced to 312 based on title and abstract. The working group members assessed 312 articles for eligibility in more detail, of which 32 articles were assessed in full-text. One article (50) could not be located in full-text and was excluded. The final literature selection included 16 articles, described in more detail in Supplemental File I, see section on supplementary data given at the end of this article. For the final recommendations, other literature (basic literature and physiologic studies) was also taken into account.

\section{Conclusions from scientific literature and directions for further research}

\subsection{Summary and interpretation of the main findings}

Sixteen studies on treatment on chronic HypoPT were included based on eligibility criteria and endpoint definition (see section 'Clinical question, eligibility criteria and endpoint definition'). Only one study (51) had a sample size of $>100$ patients. Most of the (few) available randomized studies investigated effects of rhPTH replacement therapy. Details of included studies are shown in Supplemental File I, the GRADE scoring per endpoint and evidence synthesis are provided in Supplemental File II.

\subsection{Study endpoints}

Mortality - Only one study reported data on mortality (51). No deaths were reported in this randomized study with 134 patients comparing rhPTH to placebo. The follow-up was short ( 24 weeks), not allowing conclusions regarding long-term effects on mortality.

QoL, disability and sick leave - In two studies, QoL was studied. Whereas a cohort study showed improvement in QoL compared to baseline after treatment with rhPTH (52), an advantage in QoL of therapy with rhPTH compared to placebo could not be shown in a RCT (53). No studies reported on disability or sick leave.

Cardiovascular events - Two studies (20, 51) reported one serious cardiovascular event in the
rhPTH-treated group, compared to none in the placebo group. Sample sizes were too small and follow-up too short to draw meaningful conclusions regarding cardiovascular events.

Cramps, tetany and seizures - Occurrence of cramps, tetany or seizures was not quantitatively reported in the majority of studies. In one RCT, the reported frequency of tetany did not differ materially between rhPTH and placebo group (51).

Renal function, kidney stones and calcifications Although nephrocalcinosis or nephrolithiasis is described in HypoPT, no study adequately investigated the occurrence of these conditions under different treatment regimens.

Serum and urinary calcium levels - Many studies reported in various ways on serum calcium levels. In general, calcium levels within the target range can be achieved with different treatment (combinations), and the risk of severe hypo- or hypercalcaemia is low.

\subsection{Study results in perspective}

Very little evidence is available on how best to treat HypoPT. Data on QoL and the risk of complications have just started to emerge in recent years, and clinical trials on how to optimize therapy are essentially non-existent. Importantly, the majority of studies are of limited sample size, which hampers firm conclusion especially regarding dichotomous outcomes (mortality, cardiovascular events). Also no studies are available that relate target calcium levels to clinically relevant endpoints. Thus, we do not know what the optimal calcium target is. Because of this remarkable lack of data, it is not possible to formulate recommendations based on strict evidence. This ESE guideline on treatment of chronic HypoPT in adults is, therefore, mainly based on how patients are managed in clinical practice, as reported in small case series and based on the experiences of the authors of the guideline.

Noticeably, HypoPT is one of the last major endocrine deficiency diseases not treated by hormone replacement. As HypoPT recently has been acknowledged as an orphan disease in Europe and the USA, further systematic and prospective studies on how to optimize therapy including replacement therapy with rhPTH, and avoid complications will hopefully be initiated. 


\section{Recommendations, rationale for the recommendations}

\subsection{Diagnosis}

R.1.1 We recommend considering a diagnosis of HypoPT in a patient with hypocalcaemia and inappropriately low PTH levels.

Reasoning $\boldsymbol{~ H y p o c a l c a e m i a ~ i s ~ d e f i n e d ~ a s ~ a n ~ i o n i z e d ~ o r ~}$ albumin adjusted serum total calcium level below the lower limit of the reference interval. Measurements of ionized or total calcium mostly reflect local traditions, however, ionized calcium measurements might improve diagnostic accuracy (54), and is preferred in pregnancy (see section 'Special circumstances'). A specific cut-off limit for PTH levels in the presence of hypocalcaemia cannot be defined. If parathyroid function is intact, hypocalcaemia is normally associated with (markedly) increased PTH levels (secondary hyperparathyroidism). In accordance, a diagnosis of HypoPT may be considered in a patient with hypocalcaemia even though PTH levels are within the reference interval (inappropriate normal PTH levels) $(1,2,3,4)$.

Remarks - Magnesium depletion impairs the secretion of PTH causing a state of 'functional HypoPT' and impairs effective PTH actions in target tissues. If magnesium levels are low, this should be corrected before diagnosing a patient with chronic HypoPT (55).

R.1.2 We suggest considering genetic testing and/or family screening in a patient with HypoPT of unknown aetiology.

Reasoning $\$ Non-surgical HypoPT may be due to various reasons $(38,56)$. If no obvious cause can be established, we suggest considering genetic testing and/or family screening. This may be of specific importance to younger individuals, as a genetic diagnosis may allow for genetic counselling in relation to pregnancy plans and monitoring for other possible complications that may accompany the HypoPT (e.g. renal and hearing abnormalities due to GATA3 mutation).

\subsection{General goals of management in chronic HypoPT}

R.2.1 We suggest treatment targeted to maintain calcium level (albumin adjusted total calcium or ionized calcium) in the lower part or slightly below the lower limit of the reference range (target range) with patients being free of symptoms or signs of hypocalcaemia. $(\oplus \bigcirc \bigcirc \bigcirc)$
Reasoning $\vee$ No data exist on optimal serum calcium levels during treatment of HypoPT. Aiming at low normal or slightly below the lower limit of normal for serum calcium levels seems reasonable, as this may help to lower renal calcium excretion and avoid risk of hypercalcaemia (57). Some patients may, however, need higher serum calcium levels to be free of symptoms. If the patient's wellbeing is improved by titrating treatment in such a manner that serum calcium levels are in the upper part of the reference interval, this may be accepted as no data exist on whether relatively high normal serum calcium levels are of specific harm to patients.

R.2.2 We suggest that 24-h urinary calcium excretion should be within the sex-specific reference range. $(\oplus \bigcirc \bigcirc \bigcirc)$

Reasoning $>$ In a patient with intact parathyroid function, hypercalciuria is considered a risk factor for renal stone formation. Because PTH increases the renal tubular reabsorption of calcium, chronically low PTH levels make hypercalciuria a common feature of HypoPT. Risk of renal stone disease is increased in HypoPT $(8,22)$, but no evidence exists as to whether the risk of forming or passing renal stones is associated with the amount of urinary calcium excreted in patients with HypoPT. However, if it is assumed that the pathogenesis of renal stone disease is similar in HypoPT as in hypercalciuric individuals with normal parathyroid function, it seems reasonable to aim at keeping 24-h urinary calcium within the sex-specific reference range (57) in order to prevent renal stone formation (58).

Remarks — If sex-specific reference ranges are available we suggest using them, as the urinary calcium excretion is higher in men compared to women. We suggest calcium excretion $<7.5 \mathrm{mmol} / 24-\mathrm{h}(300 \mathrm{mg} / 24-\mathrm{h})$ in men, and $<6.25 \mathrm{mmol} / 24$-h in women $(250 \mathrm{mg} / 24-\mathrm{h})$; or

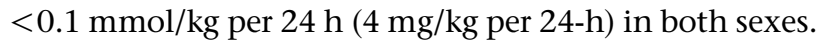

R.2.3 We suggest that serum phosphate levels should be within the reference range. $(\oplus \bigcirc \bigcirc \bigcirc)$

R.2.4 We suggest that the serum calcium-phosphate product should be below $4.4 \mathrm{mmol}^{2} / \mathrm{l}^{2}\left(55 \mathrm{mg}^{2} / \mathrm{dl}^{2}\right)$. $(\oplus \bigcirc \bigcirc \bigcirc)$

Reasoning - HypoPT is characterized by a relatively high serum phosphate level and a higher than normal calciumphosphate product. This is attributable to the lack of the phosphaturic effect of PTH, as well as an increased intestinal absorption of phosphorus due to activated 
vitamin D treatment (4, 22, 38). Risk of extra-skeletal calcifications, including nephrocalcinosis and cataract, is increased in HypoPT. It is generally assumed that this is related to high serum phosphate levels and an increased serum calcium-phosphate product, which is why it seems reasonable to aim at keeping phosphate levels within the normal range (59).

R.2.5 We suggest that serum magnesium levels should be within the reference range. $(\oplus \bigcirc \bigcirc \bigcirc)$

Reasoning - Magnesium is central for several physiological processes, including secretion and actions of PTH. Low magnesium levels may cause functional HypoPT by blunting the (residual) capacity of the parathyroid glands to secrete PTH (60). Moreover, low magnesium levels may cause symptoms similar to hypocalcaemia. Accordingly, it seems reasonable to aim at keeping serum magnesium levels within the reference range.

R.2.6 We suggest aiming at an adequate vitamin D status. $(\oplus \bigcirc \bigcirc \bigcirc)$

Reasoning - Vitamin D insufficiency has been associated with adverse effects on skeletal as well as extra-skeletal health (61). Severe vitamin D deficiency is associated with symptoms of myopathy, and patients with HypoPT often have neuromuscular complaints $(4,38,53)$. To ensure that symptoms are not caused by low vitamin D levels, it seems reasonable to ensure an adequate vitamin D status (55). A serum concentration of 25-hydroxyvitamin D (25OHD) above $50 \mathrm{nmol} / \mathrm{l}(20 \mathrm{ng} / \mathrm{ml})$ may be considered as adequate $(41,62,63)$.

Remarks - Treatment with activated vitamin D analogues does not ensure an adequate vitamin D status in terms of serum 25OHD levels. As calciferol itself may be of importance to a number of cellular processes and may undergo hydroxylation to $1,25(\mathrm{OH})_{2} \mathrm{D}$ catalyzed by local hydroxylases in different tissues (64), it seem reasonable to ensure sufficient 25OHD levels, despite treatment with activated vitamin $\mathrm{D}$ analogues.

R.2.7 We recommend to personalize treatment and focus on the overall well-being and QoL of the patient when implementing different therapeutic efforts, aiming to achieve the therapeutic goals.

Reasoning $>$ The therapeutic goals (albumin adjusted serum calcium levels $2.1-2.3 \mathrm{mmol} / 1$ or $\mathrm{S}-\mathrm{Ca}^{2+}$ levels $1.05-1.15 \mathrm{mmol} / \mathrm{l}$ ) are mainly based on reasoning according to normal physiology, assuming that normalization of biochemical indices may be advantageous to patients. However, it has to be emphasized that no firm evidence exists on long-term benefits (or harms) of achieving these therapeutic goals. Accordingly, patients cannot be ensured long-term beneficial effects, when accepting potential sideeffects to drug treatment or (troublesome) changes in lifestyle (dietary habits). Thus, we consider it inappropriate management, if therapeutic efforts have immediate negative impact on a patient's well-being or QoL.

R.2.8 We recommend providing information/education that enables patients to know the possible symptoms of hypo- or hypercalcaemia and/or complications to their disease.

Reasoning $>$ As stated in section 'Monitoring', we suggest monitoring of patients at regular time intervals. Serum calcium levels may, however, change and complications may emerge at any time, with or without any apparent reasons. Thus, we find it of importance to empower patients with knowledge of symptoms and co-morbidities and drugs that may be related to changes in the course of their disease.

Table 3 shows typical symptoms of hypo- and hypercalcaemia, of which patients should be informed. Table 4 shows co-morbidities which may occur with an increased prevalence in HypoPT. Table 5 list drugs, conditions and diseases which may interfere with calcium homeostasis. If a patient is diagnosed with one of the diseases or initiates treatment with one of the drugs, this may necessitate changes in the medical treatment of HypoPT in order to maintain normocalcaemia.

\subsection{Treatment}

R.3.1 We recommend treatment of all patients with chronic HypoPT with symptoms of hypocalcaemia and/or an albumin adjusted serum calcium level $<2.0 \mathrm{mmol} / \mathrm{l}\left(<8.0 \mathrm{mg} / \mathrm{dl} / \mathrm{S}-\mathrm{Ca}^{2+}\right.$ levels $\left.<1.00 \mathrm{mmol} / \mathrm{l}\right)$. $(\oplus \bigcirc \bigcirc \bigcirc)$

R.3.2 We suggest offering treatment to asymptomatic patients with chronic HypoPT and an albumin adjusted calcium level between $2.0 \mathrm{mmol} / 1\left(8.0 \mathrm{mg} / \mathrm{dl} / \mathrm{S}-\mathrm{Ca}^{2+}\right.$ $1.00 \mathrm{mmol} / \mathrm{l}$ ) and the lower limit of the reference range in order to assess whether this may improve their wellbeing. $(\oplus \bigcirc \bigcirc \bigcirc)$

Reasoning $>$ In chronic HypoPT, symptoms of hypocalcaemia may vary widely, from an asymptomatic state to life-threatening conditions, such as seizures, cardiac failure, bronchospasm and laryngospasm, etc. (2, 4, 22, 38). While it is obvious to recommend treatment of patients 
Table 3 Symptoms patients should be informed to allow for early detection of hypo- or hypercalcaemia.

\begin{tabular}{|c|c|}
\hline Organ System & Hypocalcaemia \\
\hline CNS & $\begin{array}{l}\text { Depression } \\
\text { Irritability } \\
\text { Confusion or disorientation } \\
\text { Seizures }\end{array}$ \\
\hline Neuromuscular & $\begin{array}{l}\text { Numbness and tingling (paraesthesia) } \\
\text { in circumoral and acral areas (fingers and toes) } \\
\text { Spasms/twitches } \\
\text { Cramps }\end{array}$ \\
\hline Cardiovascular & $\begin{array}{l}\text { Fast, slow or uneven heart rate } \\
\text { Symptoms of congestive heart failure }\end{array}$ \\
\hline Gastrointestinal & Abdominal cramps \\
\hline \multicolumn{2}{|l|}{ Renal } \\
\hline Respiratory & $\begin{array}{l}\text { Shortness of breath } \\
\text { Wheezing } \\
\text { Throat tightness }\end{array}$ \\
\hline
\end{tabular}

\begin{tabular}{l} 
Hypercalcaemia \\
\hline Weakness \\
Headache \\
Drowsiness \\
Confusion or disorientation \\
Poor memory \\
Reduced concentration \\
Muscle weakness
\end{tabular}

Fast, slow or uneven heart rate Hypertension Loss of appetite Nausea/vomiting Abdominal pain Constipation Polyuria

Dry mouth and or increased thirst

with severe symptoms of hypocalcaemia, no evidence exists on whether asymptomatic patients with biochemical hypocalcaemia should be treated. No limit of serum calcium levels have been defined below which treatment is unquestionably needed. Symptoms of hypocalcaemia do not translate directly to serum calcium levels. Sudden fluctuations in serum calcium levels may cause symptoms, even if calcium levels are (almost) normal. On the other hand, no apparent symptoms may be present, despite low calcium levels, if the hypocalcaemia has developed slowly. In a patient with intact parathyroid function, serum calcium levels are tightly regulated within a narrow range $(65,66)$. It seems likely that patients with no complaints of hypocalcaemia, despite (very) low serum calcium levels, have adapted to a new calcium homeostasis which may have blunted their hypocalcaemic symptoms. Therefore, we consider it reasonable to offer treatment to asymptomatic patients with chronic HypoPT, since treatment might improve their well-being (Fig. 1). If no improvements occur following 6-12 months of therapy, the need for treatment may be reconsidered, especially if hypocalcaemia is mild. However, vitamin D levels should be optimised.

R.3.3 We recommend the use of activated vitamin D analogues plus calcium supplements in divided doses as the primary therapy. $(\oplus \bigcirc \bigcirc \bigcirc)$

R.3.4 If activated vitamin $\mathrm{D}$ analogues are not available, we recommend treatment with calciferol (preferentially cholecalciferol).
R.3.5 We recommend that the doses of activated vitamin D analogues or cholecalciferol are titrated in such a manner that patients are without symptoms of hypocalcaemia and serum calcium levels are maintained within the target range. $(\oplus \bigcirc \bigcirc \bigcirc)$

Reasoning $\vee$ No evidence exists from controlled clinical trials on how best to treat HypoPT. Prior to the development of activated vitamin D analogues, calciferol (ergocalciferol (vitamin $\mathrm{D}_{2}$ ) or cholecalciferol (vitamin $\mathrm{D}_{3}$ )) was used in the treatment of HypoPT and supraphysiological doses of calciferol (typical 25 000-200 000 IU/day) were needed

Table 4 Co-morbidities may occur with an increased prevalence in patients with HypoPT $(8,9,17,18,21,22,53,107)$.

\begin{tabular}{|c|c|}
\hline Organ system & Co-morbidity \\
\hline Renal & $\begin{array}{l}\text { Renal stone disease and } \\
\text { impaired renal function } \\
\text { Renal calcifications }\end{array}$ \\
\hline Immunological & Infections \\
\hline Neuropsychiatric & $\begin{array}{l}\text { Neuropsychiatric diseases } \\
\text { Seizures } \\
\text { Depression } \\
\text { Impaired quality of life }\end{array}$ \\
\hline Musculoskeletal & $\begin{array}{l}\text { Muscle stiffness/pain } \\
\text { Proximal humerus fractures }\end{array}$ \\
\hline Cardiovascular & Ischemic heart disease ${ }^{a}$ \\
\hline CNS & Intracerebral calcifications ${ }^{a}$ \\
\hline Eyes & Cataract $^{\mathrm{a}}$ \\
\hline
\end{tabular}

${ }^{a} A n$ increased risk has only been documented in nonsurgical HypoPT. 
Table 5 Drug therapy and diseases may interfere with calcium homeostasis and necessitate changes in monitoring and therapy.

\begin{tabular}{|c|c|c|c|}
\hline Drug/disease & Mechanism & Possible adverse effects in HypoPT & Action \\
\hline Loop diuretics & Increased urinary calcium losses & $\begin{array}{l}\text { May aggravate hypercalciuria } \\
\text { and lower serum calcium } \\
\text { levels }\end{array}$ & Avoid if possible \\
\hline Thiazide diuretics & Decreased urinary calcium losses & $\begin{array}{l}\text { May increase serum calcium } \\
\text { levels }\end{array}$ & $\begin{array}{l}\text { May be used in a patient with } \\
\text { HypoPT (see section 'Treatment') }\end{array}$ \\
\hline Systemic glucocorticoids & $\begin{array}{l}\text { Decreased intestinal calcium } \\
\text { absorption and increased } \\
\text { urinary calcium losses }\end{array}$ & May cause hypocalcaemia & Avoid if possible \\
\hline Antiresorptive drugs & Decreased bone turnover & May cause hypocalcaemia & $\begin{array}{l}\text { Rarely needed, as HypoPT is a state } \\
\text { of (very) low bone turnover }\end{array}$ \\
\hline Proton pump inhibitors & May cause hypomagnesaemia & $\begin{array}{l}\text { May lower serum calcium levels } \\
\text { and cause symptoms similar to } \\
\text { hypocalcaemia }\end{array}$ & $\begin{array}{l}\text { Avoid if possible - otherwise } \\
\text { magnesium supplements as } \\
\text { needed }\end{array}$ \\
\hline $\begin{array}{l}\text { Chemotherapy: cisplatin, } \\
5 \text {-fluorouracil, and } \\
\text { leucovorin }\end{array}$ & May cause hypomagnesaemia & $\begin{array}{l}\text { May lower serum calcium levels } \\
\text { and cause symptoms similar to } \\
\text { hypocalcaemia }\end{array}$ & $\begin{array}{l}\text { Magnesium supplements, as } \\
\text { needed }\end{array}$ \\
\hline $\begin{array}{l}\text { Cardiac glycosides } \\
\text { (e.g. digoxin) }\end{array}$ & $\begin{array}{l}\text { Hypercalcaemia may predispose } \\
\text { to digoxin toxicity } \\
\text { Hypocalcaemia may reduce the } \\
\text { efficacy of digoxin }\end{array}$ & Arrhythmias & $\begin{array}{l}\text { Avoid if possible. If needed, close } \\
\text { monitoring by a cardiologist }\end{array}$ \\
\hline $\begin{array}{l}\text { Diarrhea/gastrointestinal } \\
\text { disease }\end{array}$ & $\begin{array}{l}\text { May reduce intestinal } \\
\text { absorption of calcium } \\
\text { and vitamin D }\end{array}$ & May cause hypocalcaemia & $\begin{array}{l}\text { Close monitoring of serum calcium } \\
\text { levels with dose adjustments as } \\
\text { needed }\end{array}$ \\
\hline $\begin{array}{l}\text { Changes in (correction of) } \\
\text { acid-base balance }^{a}\end{array}$ & $\begin{array}{l}\text { The affinity of calcium to bind to } \\
\text { proteins in serum is highly } \mathrm{pH} \\
\text { dependent - only the free } \\
\text { fraction in physiological active }\end{array}$ & $\begin{array}{l}\text { Correction of metabolic acidosis } \\
\text { may cause hypocalcaemia } \\
\text { Correction of metabolic alkalo- } \\
\text { sis may cause hypercalcaemia }\end{array}$ & \\
\hline Immobilization & $\begin{array}{l}\text { Increased bone resorption. } \\
\text { In healthy individuals, PTH } \\
\text { and 1,25-dihydroxyvitamin D } \\
\text { levels are suppressed }\end{array}$ & May cause hypercalcaemia & \\
\hline
\end{tabular}

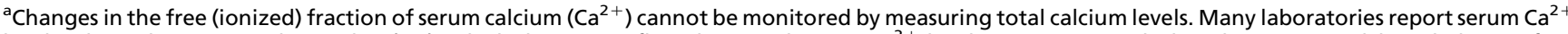
levels adjusted to a neutral $\mathrm{pH}$ value (7.4), which does not reflect the actual serum $\mathrm{Ca}^{2+}$ level in a patient with disturbances in acid-base balance. If so, patients may have symptoms despite (apparently) normal calcium levels and $\mathrm{Ca}^{2+}$ levels at actual $\mathrm{pH}$ should be requested.

to maintain normocalcaemia, usually resulting in very high plasma concentrations of 25OHD (typically 500-1000 nmol/l). Following the development of activated vitamin D analogues, small case-series showed that normocalcaemia could be achieved in HypoPT treated with activated vitamin D analogues $(67,68)$. Today, activated vitamin $\mathrm{D}$ analogues are preferred due to a shorter plasma half-life, allowing for dose titration at shorter time-intervals compared with calciferol (Table 2). Moreover, in case of intoxication, serum calcium levels will normalize faster if patients are treated with activated vitamin D analogues $(69,70)$.

Either alfacalcidol ( $1 \alpha$-hydroxyvitamin D) or calcitriol $\left(1,25(\mathrm{OH})_{2} \mathrm{D}\right)$ may be used. Effects of the different analogues have not been compared head-to-head in HypoPT. In terms of calcaemic effects, calcitriol is approximately twice as potent as alfacalcidol. To maintain serum calcium levels within the target range, the daily dose must be carefully titrated, as the dose needed varies between patients. Daily doses of calcitriol are typically $0.25-2.0 \mu \mathrm{g}$, equal to a daily dose of $0.5-4.0 \mu \mathrm{g}$ of alfacalcidol (71) (Table 2).

If serum calcium levels are slightly outside the target range, or a patient is complaining of symptoms, the daily dose of activated vitamin $\mathrm{D}$ analogue may be gradually changed (Fig. 1), i.e. daily dose of alfacalcidol may be changed by 0.5 (or 0.25 ) $\mu \mathrm{g}$ corresponding to a $0.25 \mu \mathrm{g}$ change in dose of calcitriol. Larger changes in dose may be needed in case of severe hypo- or hypercalcaemia. In order to allow for a new steady-state, dose adjustments should (if possible) not be performed more frequently than at 2-3 days' time intervals (72). If only minor symptoms or biochemical disturbances are to be adjusted, weeks may be allowed to pass between dose adjustments. If a patient is on treatment with high doses of calciferol, 2-3 months are needed between dose adjustments, before a new steady state has emerged.

Intake of calcium from supplements (or diet), not associated with active vitamin D metabolites, causes only 


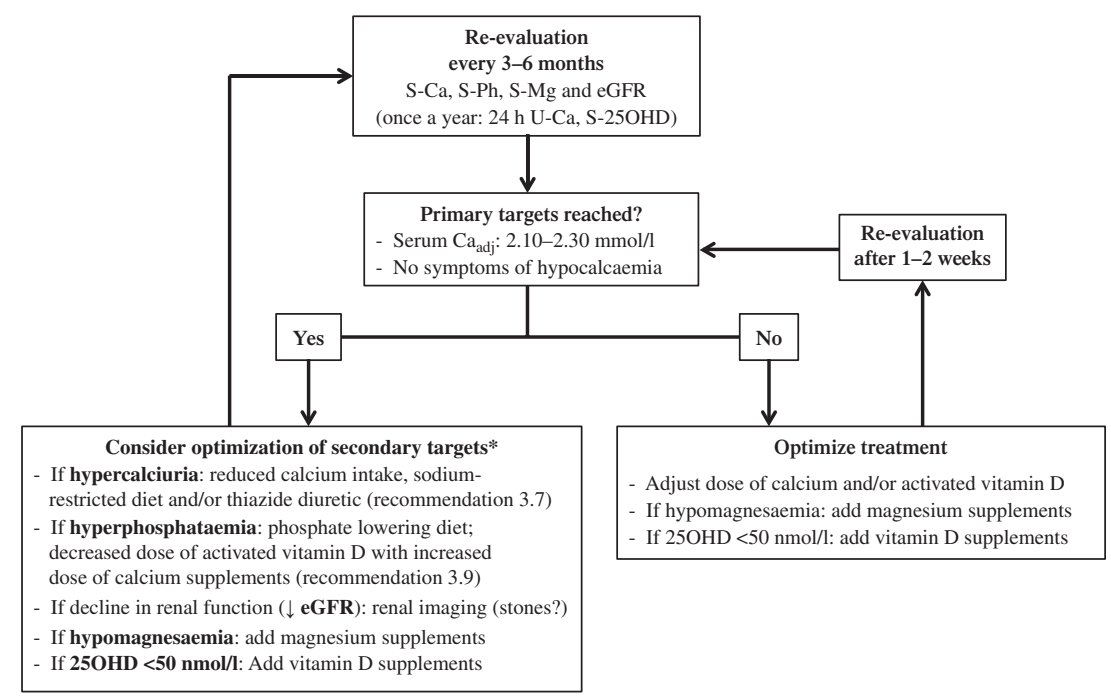

\section{Figure 1}

Monitoring and treatment of chronic hypoparathyroidism. *If dose of calcium or activated vitamin D is changed, re-evaluation of serum calcium levels is recommended after 1-2 weeks.

a relatively transient increase in serum calcium levels. Extra intake of calcium alone may be recommended pro re nata if a patient is only experiencing symptoms of hypocalcaemia once in a while.

Calcium intake An adequate daily intake of calcium from diet and supplements is advisable. Intake of calcium from dietary sources (mainly dairy products) is considered equivalent to intake from supplements (73). Patients with HypoPT are most often recommended to use calcium supplements in a total daily dose of 800-2000 mg of elemental calcium, although sometimes higher doses are used. The absorptive capacity of the intestine is probably saturated by intake of a dose of $\sim 500 \mathrm{mg}$ of calcium in one ingestion. Thus, a higher amount per dose is unlikely to be of benefit to the patient $(74,75)$. Accordingly, intake of calcium should be divided into smaller doses and spread throughout the day. Owing to interference with L-thyroxine (L-T $\left.{ }_{4}\right)$ absorption, calcium supplements should not be given together with $\mathrm{T}_{4}$ substitution (76). Different calcium salts are available as supplements. Calcium carbonate is most often used and less expensive than other calcium preparations. However, calcium carbonate requires an acidic environment for absorption and should, therefore, be taken together with a meal (73). Calcium citrate should be recommended to patients with achlorhydria or on treatment with proton pump inhibitors
(PPI; Fig. 1), as well as to patients who preferred to take supplements outside mealtimes (75).

A high intake of calcium from diet and supplements may lower the dose of vitamin $\mathrm{D}$ needed to maintain serum calcium levels within the target range. It is unknown whether a relatively high intake of calcium from supplements ( $>1000 \mathrm{mg} /$ day) is of advantage, as it may cause hypercalciuria. On the other hand calcium binds phosphorus in the intestine and may thereby lower plasma phosphate levels (77). Thus, in selected cases high doses of calcium supplement may be needed.

R.3.6 We recommend vitamin D supplementations in a daily dose of 400-800 IU to patients treated with activated vitamin $\mathrm{D}$ analogues. $(\oplus \bigcirc \bigcirc \bigcirc)$

Reasoning $>$ In order to ensure an adequate vitamin D status, a daily cholecalciferol dose of 400-800 IU (10$20 \mu \mathrm{g}$ ) will most likely ensure a serum 25OHD level above $50 \mathrm{nmol} / \mathrm{l}$ (>20 ng/ml) (Fig. 1).

R.3.7 In a patient with hypercalciuria, we suggest considering a reduction in calcium intake, a sodiumrestricted diet, and/or treatment with a thiazide diuretic. $(\oplus \bigcirc \bigcirc \bigcirc)$

Reasoning - In HypoPT, the risk of renal complications is increased $(8,22,38)$, but no data are available on whether a high renal calcium excretion is associated with the 
increased risk. However, as HypoPT causes pathological high renal calcium excretion it is reasonable to aim to normalize the 24-h urinary calcium (Fig. 1).

No data exist on whether dietary recommendations are useful in reducing urinary calcium in HypoPT. In patients with intact parathyroid function, urinary calcium is positively associated with intake of calcium and sodium $(78,79)$. Accordingly, it may be helpful to reduce the intake of sodium (Fig. 1). If patients are on treatment with a high daily dose of calcium supplements, daily dose of (activated) vitamin D may be increased in order to allow for a reduced dose of calcium supplements.

If dietary recommendations or changes in the daily dose of calcium supplements and/or activated vitamin D analogue do not reduce urinary calcium, treatment with a thiazide diuretic may be considered (Fig. 1). Thiazide diuretics have been shown to reduce urinary calcium in patients with HypoPT $(39,80,81,82,83)$. By lowering renal calcium excretion, thiazides may exert a calciumsparing effect, allowing for reduced doses of calcium supplements. Addition of amiloride to treatment with a thiazide may further lower urinary calcium losses and decrease the risk of hypokalemia. Moreover, amiloride may lower renal magnesium excretion $(19,84)$. However, no data are available on whether thiazides reduce risk of renal complications in HypoPT.

If a thiazide diuretic is prescribed, it should be noted that the hypocalciuric effect is dose-dependent, and treatment should preferably be combined with sodium restriction (85). A relatively high dose administered twice a day is often needed in order to lower $24 \mathrm{~h}$ urinary calcium, i.e. hydrochlorothiazide $50 \mathrm{mg}$ twice daily or bendroflumethiazide $5 \mathrm{mg}$ twice daily. Thiazide-like diuretics (e.g. chlorthalidone and indapamide) may, however, be administered only once daily as they have a longer duration of action.

Risk of side-effects increases with dose, and potential side-effects should be monitored closely during treatment, including blood electrolyte disturbances and blood pressure.

R.3.8 In a patient with renal stones, we recommend evaluation of renal stone risk factors and management according to relevant international guidelines.

Reasoning Although calcium-containing stones are likely to be the most frequent type of stones in HypoPT, patients with renal stones should receive a full evaluation of possible causes, and treatment should be advised according to relevant guidelines $(86,87)$ (Fig. 1).
R.3.9 In a patient with hyperphosphataemia and/or an elevated calcium-phosphate product, we suggest considering dietary interventions and/or adjustment of treatment with calcium and vitamin D analogues.

Reasoning $>$ As high serum phosphate levels and/or a high calcium-phosphate product are presumed to increase risk of extra-skeletal calcifications, interventions aiming at normalizing these biochemical indices may be considered (88) (Fig. 1), although evidence from trials are lacking. Patients may be advised to reduce intake of dietary sources rich in phosphate. As calcium binds phosphate in the intestine and calcitriol increases intestinal absorption of phosphorous, it may be considered to titrate therapy so that the daily dose of calcium supplements is increased, which may allow for a decrease in daily dose of activated vitamin D analogue. Following such changes, 24-h urinary calcium should be measured in order to ensure that patients have not developed severe hypercalciuria. No data exist on use of phosphate binders in HypoPT. Of notice, however, recent studies in patients with chronic kidney diseases (mostly not on dialysis) have suggested an increased mortality and risk of vascular calcifications in those on treatment with calcium-containing vs calcium-free phosphate binders (89). It is unknown whether lowering phosphate levels in HypoPT by increasing calcium intake is of benefit or harm to patients, which is why no firm recommendation can be stated on this matter.

R.3.10 In a patient with hypomagnesaemia, we suggest considering measures that may increase serum magnesium levels.

Reasoning $>$ Low magnesium levels are often reported in HypoPT. In addition to HypoPT as an explanation for hypomagnesaemia, other causes should be considered such as treatment with diuretics and PPI (90). In order to normalize magnesium levels, treatment with magnesium supplements or amiloride may be considered $(84,91)$ (Fig. 1)

Magnesium supplements are, however, not always well tolerated due to gastrointestinal adverse events.

In addition to lowering renal potassium excretion, amiloride has also been shown (in patients with an intact parathyroid function) to work as a magnesium-sparing diuretic $(19,84)$. If magnesium levels are chronically low, a magnesium infusion test $(0.5 \mathrm{mmol}$ of magnesium $/ \mathrm{kg}$ of body weight, in a saline solution of $500 \mathrm{ml}$, administered as an i.v. infusion over $6 \mathrm{~h}$ ) may be considered. If renal 
function is mildly impaired, the dose should be reduced. If renal function is severely impaired, this test should not be done. The results of this test will provide information on whether the patient has intracellular magnesium depletion. If 24 -h urinary magnesium excretion is $<50 \%$ of the amount infused, this signifies magnesium depletion, and the infusion itself will treat the magnesium deficiency (92).

R.3.11 We recommend against routine use of replacement therapy with PTH or PTH analogues. $(\oplus \bigcirc \bigcirc \bigcirc)$

Reasoning - Normocalcaemia can be achieved in response to s.c. injections with intact PTH or the N-terminal fragment of PTH ( $\operatorname{rhPTH}(1-34)$; teriparatide) $(20,24,51)$. Treatment with rhPTH reduces the dose of activated vitamin D analogues and calcium supplements needed to remain at target levels of biochemical indices. However, long-term beneficial effects have so far not been shown in RCTs examining other outcomes such as hypercalciuria, renal complications or QoL $(24,51,53)$. A markedly improved well-being has been reported in response to rhPTH therapy in case reports and in subgroups of patients included in trials on rhPTH therapy $(24,43,52)$. Accordingly, it is possible that PTH therapy may be of benefit for certain patients.

Remarks - Injection therapy with rhPTH is currently not marketed for the treatment of HypoPT in Europe. Intact PTH (rhPTH(1-84)) (Natpara, Shire) has recently been approved by the U.S. Food and Drug Administration for long-term treatment of HypoPT. The marketing authorization application for $\mathrm{rhPTH}(1-84)$ has been submitted to the European Medicines Agency.

\subsection{Monitoring}

R.4.1 We recommend routine biochemical monitoring of serum levels ionized or albumin adjusted total calcium, phosphate, magnesium and creatinine (eGFR), as well as assessment of symptoms of hypocalcaemia and hypercalcaemia at regular time intervals (e.g. every 3-6 months).

Reasoning - In a patient with HypoPT on stable therapy, serum calcium and renal function may change without obvious causes and without causing noticeable symptoms. Although no data exist on how best to monitor patients with HypoPT, it seems reasonable to offer biochemical screening to patients at regular time intervals (Fig. 1).

As no straightforward relationship exists between serum calcium levels and hypocalcaemic symptoms, occurrence of hypocalcaemic symptoms should also be assessed at regular time intervals, in order to assure that the treatment provides relief of symptoms, without causing side-effects.

R.4.2 Following changes in therapy, we recommend biochemical monitoring weekly or every other week.

Reasoning $>$ If the daily dose of activated vitamin $\mathrm{D}$ or calcium is changed or if new drug treatment is introduced (such as thiazide diuretics), serum levels of calcium, phosphate, magnesium and creatinine (eGFR) should be closely monitored for the first weeks (Fig. 1). In case of severe hypo- or hypercalcaemia, more frequent monitoring (several times a week) may be needed.

R.4.3 We suggest considering monitoring of 24-h urinary calcium excretion at regular time intervals (e.g. once a year or every second year).

Reasoning $~-$ As hypercalciuria is considered a risk factor for renal calcifications, assessment of 24-h urinary calcium at regular time intervals may allow for early intervention if hypercalciuria is present. No data are, however, available on whether this will help to reduce long-term morbidity.

R.4.4 We recommend renal imaging if a patient has symptoms of renal stone disease or if serum creatinine levels start to rise.

Reasoning $\boldsymbol{~ R ~ R i s k s ~ o f ~ r e n a l ~ c o m p l i c a t i o n s ~ a r e ~ s i g n i f i c a n t l y ~}$ increased in HypoPT (8). Deterioration of renal function, as detected by increased creatinine levels, or symptoms compatible with renal stone disease should be carefully investigated (Fig. 1). It is unknown whether screening for renal calcifications by use of routine renal imaging at certain time intervals is advantageous.

R.4.5 We suggest monitoring for development of signs or symptoms of co-morbidities at regular time intervals (e.g. yearly).

Reasoning $>$ HypoPT is associated with a number of co-morbidities (Table 4). Early detection of such complications may be of importance, which is why it seems reasonable to assess, in a systematic manner, whether patients are experiencing symptoms which may indicate emerging complications. No study in patients with HypoPT has shown the beneficial effect of screening for these co-morbidities.

As certain drugs/diseases and conditions may interfere with the treatment of HypoPT, awareness of concomitant treatment with other drugs is also needed (Table 5). 
R.4.6 We advise against routine monitoring of BMD by DXA scans.

Reasoning - HypoPT is a state of very low bone turnover and $\mathrm{BMD}$ is not expected to decrease during the course of HypoPT (93) unless other disorders or drug therapies occur (e.g. glucocorticoids).

\subsection{Special circumstances}

R.5.1 ADH: we recommend frequent monitoring of patients with $\mathrm{ADH}$, who are being treated with calcium and/or activated vitamin D analogues, as such patients may be at high risk of hypercalciuria and renal complications.

Reasoning $-\mathrm{ADH}$ is caused by an activating mutation in the CASR. A diagnosis of ADH can be established through genetic testing (OMIM 601198). The gain of function mutation causes a lowering of the calcium set-point in the parathyroid glands. At equivalent serum calcium levels, patients with $\mathrm{ADH}$ have lower PTH levels than normal individuals. In a strict sense, this is not a state of HypoPT, as the parathyroid glands are well preserved although less responsive to a hypocalcaemic challenge (94). The CASR is also expressed in the renal tubule, and renal calcium excretion is often markedly increased in patients with $\mathrm{ADH}$ who are at increased risk of renal complications $(56,95)$. In case reports, thiazide diuretics have been reported to reduce urinary calcium in patients with $\operatorname{ADH}(39,81,96)$.

R.5.2 Pregnancy and breastfeeding: we suggest treatment with activated vitamin $\mathrm{D}$ analogues and calcium supplements as in non-pregnant women.

Reasoning Although pregnancy-related increases in $1,25(\mathrm{OH})_{2} \mathrm{D}$ initially and in PTHrP later would suggest that calcium and vitamin $\mathrm{D}$ analogues may need reducing during pregnancy, this is often not the case. Especially after the 20th week of pregnancy, many women with HypoPT actually need gradually higher doses of activated vitamin D analogues to maintain serum calcium levels in the target range and avoid symptoms of hypocalcaemia $(97,98,99)$.

There are relatively few case reports and no trials that test management strategies for women with chronic HypoPT during pregnancy and lactation. The largest series included 12 pregnant women who were treated with oral calcium and calcitriol and reported a high level of overall safety during pregnancy (30) (see Supplemental File III). These and other authors have recommended oral calcium supplements to be combined with calcitriol (doses of 0.25 $3.0 \mu \mathrm{g} /$ day) for treatment of chronic HypoPT during pregnancy $(27,30)$. Other reports support the recommendation to use calcitriol in pregnancy and lactation, due to it potency and short half-life, compared to other forms of vitamin D $(97,98,99)$, but the amount of evidence is low.

During lactation, PTHrP levels rise and many women develop hypercalcaemia if calcium and activated vitamin D supplements are not often dramatically reduced. Then, gradually after weaning, these changes in maternal hormones regress, and a new steady-state is achieved. Generally, women with HypoPT stabilize on a similar, if not the same medical regimen as pre-pregnancy, but careful adjustment and monitoring of these patients are needed to assure smooth transition.

R.5.3 We suggest monitoring serum ionized calcium regularly (every 2 nd or 3rd week) during pregnancy and breastfeeding with levels to be kept at the lower end of the normal range (serum albumin adjusted total calcium is also acceptable).

Reasoning $>$ Serum total calcium falls in normal pregnancy due to haemodilution-induced reductions in serum albumin levels, but ionized calcium remains stable (29, 100). Thus, in pregnant women with HypoPT, serum ionized calcium is the preferred parameter that should be frequently monitored (e.g. every 2 or 3 weeks) $(25,27)$. Alternatively, albumin-corrected total serum is an acceptable parameter to follow (25). Levels of serum calcium are recommended to be kept at the lower end of the normal range in pregnant women with chronic HypoPT. During lactation, there are high rates of bone resorption due to breast tissue production of PTHrP (101). These events mandate careful monitoring of serum calcium levels in women with HypoPT who are nursing because hypercalcaemia is commonly encountered if vitamin D analogue therapy is not quickly adjusted. The onset of hypercalcaemia during breastfeeding can be immediate $(97,101,102$, $103,104,105)$ and has even been reported when treating women with HypoPT with longer-acting ergocalciferol, who did not breastfeed (106). Gradually after weaning, the above changes in maternal hormones regress, and a new steady-state is achieved.

R.5.4 We recommend that the pediatrician and or neonatologist be informed of maternal HypoPT and be involved in the immediate care and monitoring of the infant for possible consequences of the treatment of the mother and the underlying maternal disorder. 
Reasoning $>$ Depending on the ease and degree of control of the maternal serum calcium and phosphate during pregnancy, the neonate may be at greater risk of disordered parathyroid function and serum calcium postnatally. The neonate is at risk for suppressed PTH secretion, manifested as neonatal hypocalcaemia, if the mother has been hypercalcaemic during pregnancy. Alternatively, the infant may demonstrate secondary hyperparathyroidism with bone demineralization and its consequences, if the mother has been hypocalcaemic significantly during pregnancy.

\section{Supplementary data}

This is linked to the online version of the paper at http://dx.doi.org/10.1530/ EJE-15-0628.

\section{Declaration of interest}

The guideline was developed in collaboration with CBO - Dutch Institute for Health Care Improvement. D M Shoback is on the advisory board and has received travel grants for/from NPS Pharmaceuticals and is also a consultant to Kai Pharmaceutical and XOMA. L Rejnmark is an advisory board member for NPS Pharmaceuticals and has received speakers fee from NPS Pharma, Amgen, Eli Lilly, Novo Nordic and Takeda. C Marcocci is a member of advisory boards for Amgen and has received speakers fee/travel support from Amgen, Abiogen. The rest of the working group has nothing to declare for this guideline.

\section{Funding}

This guideline was sponsored by the European Society of Endocrinology.

\section{Acknowledgements}

The authors of the guideline want to thank and acknowledge Kari Lima, $\mathrm{MD}, \mathrm{PhD}$, Akershus University Hospital, Norway for her expert review before sending the guideline out to ESE members.

\section{References}

1 Cusano NE, Rubin MR \& Bilezikian JP. Parathyroid hormone therapy for hypoparathyroidism. Best Practice \& Research. Clinical Endocrinology \& Metabolism 201529 47-55. (doi:10.1016/j.beem.2014.09.001)

2 Khan MI, Waguespack SG \& Hu MI. Medical management of postsurgical hypoparathyroidism. Endocrine Practice 201117 (Suppl 1) 18-25. (doi:10.4158/EP10302.RA)

3 Rejnmark L, Underbjerg L \& Sikjaer T. Therapy of hypoparathyroidism by replacement with parathyroid hormone. Scientifica 20142014 765629. (doi:10.1155/2014/765629)

4 Shoback D. Clinical practice. Hypoparathyroidism. New England Journal of Medicine 2008359 391-403. (doi:10.1056/NEJMcp0803050)

5 Puzziello A, Rosato L, Innaro N, Orlando G, Avenia N, Perigli G, Calò PG \& De Palma M. Hypocalcemia following thyroid surgery: incidence and risk factors. A longitudinal multicenter study comprising 2,631 patients. Endocrine 201447 537-542. (doi:10.1007/s12020014-0209-y)
6 Betterle C, Garelli S \& Presotto F. Diagnosis and classification of autoimmune parathyroid disease. Autoimmunity Reviews 201413 417-422. (doi:10.1016/j.autrev.2014.01.044)

7 Lima K, Abrahamsen TG, Wolff AB, Husebye E, Alimohammadi M, Kämpe $\mathrm{O} \&$ Følling I. Hypoparathyroidism and autoimmunity in the 22q11.2 deletion syndrome. European Journal of Endocrinology 2011 165 345-352. (doi:10.1530/EJE-10-1206)

8 Underbjerg L, Sikjaer T, Mosekilde L \& Rejnmark L. Cardiovascular and renal complications to postsurgical hypoparathyroidism: a Danish nationwide controlled historic follow-up study. Journal of Bone and Mineral Research 201328 2277-2285. (doi:10.1002/jbmr.1979)

9 Underbjerg L, Sikjaer T, Mosekilde L \& Rejnmark L. The epidemiology of non-surgical hypoparathyroidism in Denmark: a nationwide case finding study. Journal of Bone and Mineral Research, 2015. In press. (doi:10.1002/jbmr.2501)

10 Powers J, Joy K, Ruscio A \& Lagast H. Prevalence and incidence of hypoparathyroidism in the United States using a large claims database. Journal of Bone and Mineral Research 201328 2570-2576. (doi:10.1002/jbmr.2004)

11 Lorente-Poch L, Sancho JJ, Munoz-Nova JL, Sanchez-Velazquez P \& Sitges-Serra A. Defining the syndromes of parathyroid failure after total thyroidectomy. Gland Surgery 20154 82-90.

12 Edafe O, Antakia R, Laskar N, Uttley L \& Balasubramanian SP. Systematic review and meta-analysis of predictors of post-thyroidectomy hypocalcaemia. British Journal of Surgery 2014101 307-320. (doi:10.1002/bjs.9384)

13 Sitges-Serra A, Ruiz S, Girvent M, Manjon H, Duenas JP \& Sancho JJ. Outcome of protracted hypoparathyroidism after total thyroidectomy. British Journal of Surgery 201097 1687-1695. (doi:10.1002/bjs.7219)

14 Barczynski M, Cichon S \& Konturek A. Which criterion of intraoperative $\mathrm{PTH}$ assay is the most accurate in prediction of true serum calcium levels after thyroid surgery? Langenbeck's Archives of Surgery 2007392 693-698. (doi:10.1007/s00423-007-0165-6)

15 Grodski S \& Serpell J. Evidence for the role of perioperative PTH measurement after total thyroidectomy as a predictor of hypocalcemia. World Journal of Surgery 200832 1367-1373. (doi:10.1007/s00268-008-9545-5)

16 Lorente-Poch L, Sancho JJ, Ruiz S \& Sitges-Serra A. Importance of in situ preservation of parathyroid glands during total thyroidectomy. British Journal of Surgery 2015102 359-367. (doi:10.1002/bjs.9676)

17 Arlt W, Fremerey C, Callies F, Reincke M, Schneider P, Timmermann W \& Allolio B. Well-being, mood and calcium homeostasis in patients with hypoparathyroidism receiving standard treatment with calcium and vitamin D. European Journal of Endocrinology 2002146 215-222. (doi:10.1530/eje.0.1460215)

18 Cusano NE, Rubin MR, McMahon DJ, Irani D, Tulley A, Sliney J Jr \& Bilezikian JP. The effect of PTH(1-84) on quality of life in hypoparathyroidism. Journal of Clinical Endocrinology and Metabolism 201398 2356-2361. (doi:10.1210/jc.2013-1239)

19 Murdoch DL, Forrest G, Davies DL \& McInnes GT. A comparison of the potassium and magnesium-sparing properties of amiloride and spironolactone in diuretic-treated normal subjects. British Journal of Clinical Pharmacology 199335 373-378. (doi:10.1111/j.1365-2125. 1993.tb04153.x)

20 Sikjaer T, Rejnmark L, Rolighed L, Heickendorff L \& Mosekilde L. The effect of adding PTH(1-84) to conventional treatment of hypoparathyroidism: a randomized, placebo-controlled study. Journal of Bone and Mineral Research 201126 2358-2370. (doi:10.1002/jbmr.470)

21 Underbjerg L, Sikjaer T, Mosekilde L \& Rejnmark L. Postsurgical hypoparathyroidism - risk of fractures, psychiatric diseases, cancer, cataract, and infections. Journal of Bone and Mineral Research 201429 2504-2510. (doi:10.1002/jbmr.2273)

22 Mitchell DM, Regan S, Cooley MR, Lauter KB, Vrla MC, Becker CB, Burnett-Bowie SA \& Mannstadt M. Long-term follow-up of patients with hypoparathyroidism. Journal of Clinical Endocrinology and Metabolism 201297 4507-4514. (doi:10.1210/jc.2012-1808) 
23 Rubin MR, Dempster DW, Zhou H, Shane E, Nickolas T, Sliney J Jr, Silverberg SJ \& Bilezikian JP. Dynamic and structural properties of the skeleton in hypoparathyroidism. Journal of Bone and Mineral Research 200823 2018-2024. (doi:10.1359/jbmr.080803)

24 Winer KK, Ko CW, Reynolds JC, Dowdy K, Keil M, Peterson D, Gerber LH, McGarvey C \& Cutler GB Jr. Long-term treatment of hypoparathyroidism: a randomized controlled study comparing parathyroid hormone-(1-34) versus calcitriol and calcium. Journal of Clinical Endocrinology and Metabolism 200388 4214-4220. (doi:10.1210/jc.2002-021736)

25 Cooper MS. Disorders of calcium metabolism and parathyroid disease. Best Practice \& Research. Clinical Endocrinology \& Metabolism 201125 975-983. (doi:10.1016/j.beem.2011.07.001)

26 Kovacs CS \& Kronenberg HM. Maternal-fetal calcium and bone metabolism during pregnancy, puerperium, and lactation. Endocrine Reviews 199718 832-872.

27 Kovacs CS \& Fuleihan G. Calcium and bone disorders during pregnancy and lactation. Endocrinology and Metabolism Clinics of North America 200635 21-51, v. (doi:10.1016/j.ecl.2005.09.004)

28 Kovacs CS. Bone development and mineral homeostasis in the fetus and neonate: roles of the calciotropic and phosphotropic hormones. Physiological Reviews 201494 1143-1218. (doi:10.1152/physrev. 00014.2014)

29 Mestman JH. Parathyroid disorders of pregnancy. Seminars in Perinatology 199822 485-496. (doi:10.1016/S0146-0005(98)80028-1)

30 Callies F, Arlt W, Scholz HJ, Reincke M \& Allolio B. Management of hypoparathyroidism during pregnancy - report of twelve cases. European Journal of Endocrinology 1998139 284-289. (doi:10.1530/eje.0.1390284)

31 Eastell R, Edmonds CJ, de Chayal RC \& McFadyen IR. Prolonged hypoparathyroidism presenting eventually as second trimester abortion. BMJ 1985291 955-956. (doi:10.1136/bmj.291.6500.955)

32 Krysiak R, Kobielusz-Gembala I \& Okopien B. Hypoparathyroidism in pregnancy. Gynecological Endocrinology 201127 529-532. (doi:10. 3109/09513590.2010.507284)

33 Alikasifoglu A, Gonc EN, Yalcin E, Dogru D \& Yordam N. Neonatal hyperparathyroidism due to maternal hypoparathyroidism and vitamin D deficiency: a cause of multiple bone fractures. Clinical Pediatrics 200544 267-269. (doi:10.1177/000992280504400312)

34 Demirel N, Aydin M, Zenciroglu A, Okumus N, Cetinkaya S, Yildiz YT $\&$ Ipek MS. Hyperparathyroidism secondary to maternal hypoparathyroidism and vitamin D deficiency: an uncommon cause of neonatal respiratory distress. Annals of Tropical Paediatrics 200929 149-154. (doi:10.1179/146532809X440770)

35 Landing BH \& Kamoshita S. Congenital hyperparathyroidism secondary to maternal hypoparathyroidism. Journal of Pediatrics 1970 77 842-847. (doi:10.1016/S0022-3476(70)80245-1)

36 Loughead JL, Mughal Z, Mimouni F, Tsang RC \& Oestreich AE. Spectrum and natural history of congenital hyperparathyroidism secondary to maternal hypocalcemia. American Journal of Perinatology 19907 350-355. (doi:10.1055/s-2007-999521)

37 Cooper MS \& Gittoes NJ. Diagnosis and management of hypocalcaemia. BMJ 2008336 1298-1302. (doi:10.1136/bmj.39582.589433.BE)

38 Bilezikian JP, Khan A, Potts JT Jr, Brandi ML, Clarke BL, Shoback D, Jüppner H, D'Amour P, Fox J, Rejnmark L et al. Hypoparathyroidism in the adult: epidemiology, diagnosis, pathophysiology, target-organ involvement, treatment, and challenges for future research. Journal of Bone and Mineral Research 201126 2317-2337. (doi:10.1002/jbmr.483)

39 Porter RH, Cox BG, Heaney D, Hostetter TH, Stinebaugh BJ \& Suki WN. Treatment of hypoparathyroid patients with chlorthalidone. New England Journal of Medicine 1978298 577-581. (doi:10.1056/NEJM197803162981101)

40 Atkinson SA. The new dietary reference intakes from the Institute of Medicine for calcium and vitamin D. Perspective Infirmière: Revue Officielle de l'Ordre des Infirmières et Infirmiers du Québec 201185.

41 Ross AC, Manson JE, Abrams SA, Aloia JF, Brannon PM, Clinton SK, Durazo-Arvizu RA, Gallagher JC, Gallo RL, Jones G et al. The 2011 report on dietary reference intakes for calcium and vitamin $\mathrm{D}$ from the Institute of Medicine: what clinicians need to know. Journal of Clinical Endocrinology and Metabolism 2011 96 53-58. (doi:10.1210/jc.2010-2704)

42 Horwitz MJ \& Stewart AF. Hypoparathyroidism: is it time for replacement therapy? Journal of Clinical Endocrinology and Metabolism 200893 3307-3309. (doi:10.1210/jc.2008-1216)

43 Winer KK, Sinaii N, Peterson D, Sainz B Jr \& Cutler GB Jr. Effects of once versus twice-daily parathyroid hormone 1-34 therapy in children with hypoparathyroidism. Journal of Clinical Endocrinology and Metabolism 200893 3389-3395. (doi:10.1210/jc.2007-2552)

44 Winer KK, Zhang B, Shrader JA, Peterson D, Smith M, Albert PS \& Cutler GB Jr. Synthetic human parathyroid hormone 1-34 replacement therapy: a randomized crossover trial comparing pump versus injections in the treatment of chronic hypoparathyroidism. Journal of Clinical Endocrinology and Metabolism 201297 391-399. (doi:10.1210/ jc.2011-1908)

45 Guyatt G, Oxman AD, Akl EA, Kunz R, Vist G, Brozek J, Norris S, FalckYtter Y, Glasziou P, DeBeer $\mathrm{H}$ et al. GRADE guidelines: 1. IntroductionGRADE evidence profiles and summary of findings tables. Journal of Clinical Epidemiology 201164 383-394. (doi:10.1016/j.jclinepi.2010. 04.026)

46 Guyatt GH, Oxman AD, Kunz R, Atkins D, Brozek J, Vist G, Alderson P, Glasziou P, Falck-Ytter Y, Schünemann HJ et al. GRADE guidelines: 2. Framing the question and deciding on important outcomes. Journal of Clinical Epidemiology 201164 395-400. (doi:10.1016/j.jclinepi.2010. 09.012)

47 Balshem H, Helfand M, Schunemann HJ, Oxman AD, Kunz R, Brozek J, Vist GE, Falck-Ytter Y, Meerpohl J, Norris $\mathrm{S}$ et al. GRADE guidelines: 3 . Rating the quality of evidence. Journal of Clinical Epidemiology 201164 401-406. (doi:10.1016/j.jclinepi.2010.07.015)

48 Andrews J, Guyatt G, Oxman AD, Alderson P, Dahm P, Falck-Ytter Y, Nasser M, Meerpohl J, Post PN, Kunz R et al. GRADE guidelines: 14 . Going from evidence to recommendations: the significance and presentation of recommendations. Journal of Clinical Epidemiology 201366 719-725. (doi:10.1016/j.jclinepi.2012.03.013)

49 Guyatt GH, Schunemann HJ, Djulbegovic B \& Akl EA. Guideline panels should not GRADE good practice statements. Journal of Clinical Epidemiology 201568 597-600. (doi:10.1016/j.jclinepi.2014.12.011)

50 Arata RO, Mautalen CA, Geffner D \& Horwith M. Effect of hydrochlorothiazide upon serum and urinary calcium in patients with hypoparathyroidism. Medicina 197434 463-470.

51 Mannstadt M, Clarke BL, Vokes T, Brandi ML, Ranganath L, Fraser WD, Lakatos P, Bajnok L, Garceau R, Mosekilde L et al. Efficacy and safety of recombinant human parathyroid hormone (1-84) in hypoparathyroidism (REPLACE): a double-blind, placebo-controlled, randomised, phase 3 study. Lancet. Diabetes \& Endocrinology 20131 275-283. (doi:10.1016/S2213-8587(13)70106-2)

52 Cusano NE, Rubin MR, McMahon DJ, Irani D, Anderson L, Levy E \& Bilezikian JP. PTH(1-84) is associated with improved quality of life in hypoparathyroidism through 5 years of therapy. Journal of Clinical Endocrinology and Metabolism 201499 3694-3699. (doi:10.1210/jc. 2014-2267)

53 Sikjaer T, Rolighed L, Hess A, Fuglsang-Frederiksen A, Mosekilde L \& Rejnmark L. Effects of PTH(1-84) therapy on muscle function and quality of life in hypoparathyroidism: results from a randomized controlled trial. Osteoporosis International 201425 1717-1726. (doi:10.1007/s00198-014-2677-6)

54 Ong GS, Walsh JP, Stuckey BG, Brown SJ, Rossi E, Ng JL, Nguyen HH, Kent GN \& Lim EM. The importance of measuring ionized calcium in characterizing calcium status and diagnosing primary hyperparathyroidism. Journal of Clinical Endocrinology and Metabolism 201297 3138-3145. (doi:10.1210/jc.2012-1429)

55 Kannan S, Mahadevan S, Velayutham P, Bharath R, Kumaravel V, Muthukumaran J \& Premkumar A. Estimation of magnesium in patients with functional hypoparathyroidism. Indian Journal of Endocrinology and Metabolism 201418 821-825. (doi:10.4103/2230-8210.141365) 
56 Thakker RV. Genetic developments in hypoparathyroidism. Lancet 2001357 974-976. (doi:10.1016/S0140-6736(00)04254-9)

57 Rathod A, Bonny O, Guessous I, Suter PM, Conen D, Erne P, Binet I, Gabutti L, Gallino A, Muggli F et al. Association of urinary calcium excretion with serum calcium and vitamin D levels. Clinical Journal of the American Society of Nephrology $201510452-462$. (doi:10.2215/CJN. 12511213)

58 Coe FL, Evan A \& Worcester E. Pathophysiology-based treatment of idiopathic calcium kidney stones. Clinical Journal of the American Society of Nephrology 20116 2083-2092. (doi:10.2215/CJN.11321210)

59 Caudarella R, Vescini F, Buffa A \& Francucci CM. Hyperphosphatemia: effects on bone metabolism and cardiovascular risk. Journal of Endocrinological Investigation 200730 (6 Suppl) 29-34.

60 Rodriguez-Ortiz ME, Canalejo A, Herencia C, Martínez-Moreno JM, Peralta-Ramírez A, Perez-Martinez P, Navarro-González JF, Rodríguez M, Peter M, Gundlach K et al. Magnesium modulates parathyroid hormone secretion and upregulates parathyroid receptor expression at moderately low calcium concentration. Nephrology, Dialysis, Transplantation 201429 282-289. (doi:10.1093/ndt/gft400)

61 Autier P, Boniol M, Pizot C \& Mullie P. Vitamin D status and ill health: a systematic review. Lancet. Diabetes \& Endocrinology 20142 76-89. (doi:10.1016/S2213-8587(13)70165-7)

62 Aloia JF. Clinical Review: The 2011 report on dietary reference intake for vitamin D: where do we go from here? Journal of Clinical Endocrinology and Metabolism 201196 2987-2996. (doi:10.1210/jc.2011-0090)

63 Francis RM, Aspray TJ, Bowring CE, Fraser WD, Gittoes NJ, Javaid MK, Macdonald HM, Patel S, Selby PL \& Tanna N. National Osteoporosis Society practical clinical guideline on vitamin $\mathrm{D}$ and bone health. Maturitas 201580 119-121. (doi:10.1016/j.maturitas.2014.11.018)

64 Hobaus J, Thiem U, Hummel DM \& Kallay E. Role of calcium, vitamin $\mathrm{D}$, and the extrarenal vitamin D hydroxylases in carcinogenesis. Anti-Cancer Agents in Medicinal Chemistry 201313 20-35. (doi:10.2174/ $187152013804487434)$

65 O'Seaghdha CM, Yang Q, Glazer NL, Leak TS, Dehghan A, Smith AV, Kao WH, Lohman K, Hwang SJ, Johnson AD et al. Common variants in the calcium-sensing receptor gene are associated with total serum calcium levels. Human Molecular Genetics 201019 4296-4303. (doi:10. 1093/hmg/ddq342)

66 Pearce S. Extracellular "calcistat" in health and disease. Lancet 1999 353 83-84. (doi:10.1016/S0140-6736(05)76148-1)

67 Davies M, Taylor CM, Hill LF \& Stanbury SW. 1,25-Dihydroxycholecalciferol in hypoparathyroidism. Lancet 19771 55-59. (doi:10.1016/ S0140-6736(77)91077-7)

68 Hill LF, Davies M, Taylor CM \& Standbury SW. Treatment of hypoparathyroidism with 1,25-dihydroxycholecalciferol. Clinical Endocrinology 19765 (Suppl) 167S-173S. (doi:10.1111/j.1365-2265. 1976.tb03824.x)

69 Kanis JA, Russell RG \& Smith R. Physiological and therapeutic differences between vitamin D, its metabolites and analogues. Clinical Endocrinology 19777 (Suppl) 191s-201s. (doi:10.1111/j.1365-2265. 1977.tb03381.x)

70 Kanis JA \& Russell RG. Rate of reversal of hypercalcaemia and hypercalciuria induced by vitamin $\mathrm{D}$ and its $1 \alpha$-hydroxylated derivatives. BMJ 19771 78-81. (doi:10.1136/bmj.1.6053.78)

71 Okano K, Furukawa Y, Morii H \& Fujita T. Comparative efficacy of various vitamin $\mathrm{D}$ metabolites in the treatment of various types of hypoparathyroidism. Journal of Clinical Endocrinology and Metabolism 198255 238-243. (doi:10.1210/jcem-55-2-238)

72 Seino Y, Tanaka H, Yamaoka K \& Yabuuchi H. Circulating 1 $\alpha, 25-$ dihydroxyvitamin $\mathrm{D}$ levels after a single dose of 1 $\alpha, 25$-dihydroxyvitamin D3 or $1 \alpha$-hydroxyvitamin D3 in normal men. Bone and Mineral 19872 479-485.

73 Recker RR \& Heaney RP. The effect of milk supplements on calcium metabolism, bone metabolism and calcium balance. American Journal of Clinical Nutrition 198541 254-263.
74 Harvey JA, Zobitz MM \& Pak CY. Dose dependency of calcium absorption: a comparison of calcium carbonate and calcium citrate. Journal of Bone and Mineral Research 19883 253-258. (doi:10.1002/ jbmr.5650030303)

75 Straub DA. Calcium supplementation in clinical practice: a review of forms, doses, and indications. Nutrition in Clinical Practice 200722 286-296. (doi:10.1177/0115426507022003286)

76 Zamfirescu I \& Carlson HE. Absorption of levothyroxine when coadministered with various calcium formulations. Thyroid 201121 483-486. (doi:10.1089/thy.2010.0296)

77 Malberti F. Hyperphosphataemia: treatment options. Drugs 201373 673-688. (doi:10.1007/s40265-013-0054-y)

78 el-Hajj FG, Seifter J, Scott J \& Brown EM. Calcium-regulated renal calcium handling in healthy men: relationship to sodium handling. Journal of Clinical Endocrinology and Metabolism 199883 2366-2372.

79 Karp HJ, Ketola ME \& Lamberg-Allardt CJ. Acute effects of calcium carbonate, calcium citrate and potassium citrate on markers of calcium and bone metabolism in young women. British Journal of Nutrition 2009102 1341-1347. (doi:10.1017/S0007114509990195)

80 Kurzel RB \& Hagen GA. Use of thiazide diuretics to reduce the hypercalciuria of hypoparathyroidism during pregnancy. American Journal of Perinatology 19907 333-336. (doi:10.1055/s-2007-999516)

81 Newman GH, Wade M \& Hosking DJ. Effect of bendrofluazide on calcium reabsorption in hypoparathyroidism. European Journal of Clinical Pharmacology 198427 41-46. (doi:10.1007/BF02395204)

82 Parfitt AM. Thiazide-induced hypercalcemia in vitamin D-treated hypoparathyroidism. Annals of Internal Medicine 197277 557-563. (doi:10.7326/0003-4819-77-4-557)

83 Santos F, Smith MJ \& Chan JC. Hypercalciuria associated with longterm administration of calcitriol (1,25-dihydroxyvitamin D3). Action of hydrochlorothiazide. American Journal of Diseases of Children 1986 140 139-142. (doi:10.1001/archpedi.1986.02140160057032)

84 Maschio G, Tessitore N, D'Angelo A, Fabris A, Pagano F, Tasca A, Graziani G, Aroldi A, Surian M, Colussi G et al. Prevention of calcium nephrolithiasis with low-dose thiazide, amiloride and allopurinol. American Journal of Medicine 198171 623-626. (doi:10.1016/00029343(81)90215-1)

85 Rejnmark L, Vestergaard P, Pedersen AR, Heickendorff L, Andreasen F \& Mosekilde L. Dose-effect relations of loop- and thiazide-diuretics on calcium homeostasis: a randomized, double-blinded Latin-square multiple cross-over study in postmenopausal osteopenic women. European Journal of Clinical Investigation 200333 41-50. (doi:10.1046/j. 1365-2362.2003.01103.x)

86 Pearle MS, Goldfarb DS, Assimos DG, Curhan G, Denu-Ciocca CJ, Matlaga BR, Monga M, Penniston KL, Preminger GM, Turk TM et al. Medical management of kidney stones: AUA guideline. Journal of Urology 2014192 316-324. (doi:10.1016/j.juro.2014.05.006)

87 Qaseem A, Dallas P, Forciea MA, Starkey M \& Denberg TD. Dietary and pharmacologic management to prevent recurrent nephrolithiasis in adults: a clinical practice guideline from the American College of Physicians. Annals of Internal Medicine 2014161 659-667. (doi:10. 7326/M13-2908)

88 Cannata-Andia JB \& Rodriguez-Garcia M. Hyperphosphataemia as a cardiovascular risk factor - how to manage the problem. Nephrology, Dialysis, Transplantation 200217 (Suppl 11) 16-19. (doi:10.1093/ndt/ 17.suppl_11.16)

89 Ketteler M, Elder GJ, Evenepoel P, Ix JH, Jamal SA, Lafage-Proust MH, Shroff R, Thadhani RI, Tonelli MA, Kasiske BL et al. Revisiting KDIGO clinical practice guideline on chronic kidney disease-mineral and bone disorder: a commentary from a Kidney Disease: Improving Global Outcomes controversies conference. Kidney International 2015 87 502-528. (doi:10.1038/ki.2014.425)

90 Epstein M, McGrath S \& Law F. Proton-pump inhibitors and hypomagnesemic hypoparathyroidism. New England Journal of Medicine 2006355 1834-1836. (doi:10.1056/NEJMc066308) 
91 Lubi M, Tammiksaar K, Matjus S, Vasar E \& Volke V. Magnesium supplementation does not affect blood calcium level in treated hypoparathyroid patients. Journal of Clinical Endocrinology and Metabolism 201297 E2090-E2092. (doi:10.1210/jc.2012-2301)

92 Fatemi S, Ryzen E, Flores J, Endres DB \& Rude RK. Effect of experimental human magnesium depletion on parathyroid hormone secretion and 1,25-dihydroxyvitamin D metabolism. Journal of Clinical Endocrinology and Metabolism 199173 1067-1072. (doi:10.1210/jcem73-5-1067)

93 Touliatos JS, Sebes JI, Hinton A, McCommon D, Karas JG \& Palmieri GM. Hypoparathyroidism counteracts risk factors for osteoporosis. American Journal of Medical Sciences 1995310 56-60. (doi:10.1097/00000441-199508000-00003)

94 Heath H III, Odelberg S, Jackson CE, Teh BT, Hayward N, Larsson C, Buist NR, Krapcho KJ, Hung BC, Capuano IV et al. Clustered inactivating mutations and benign polymorphisms of the calcium receptor gene in familial benign hypocalciuric hypercalcemia suggest receptor functional domains. Journal of Clinical Endocrinology and Metabolism 199681 1312-1317. (doi:10.1210/jcem.81.4.8636323)

95 Lienhardt A, Bai M, Lagarde JP, Rigaud M, Zhang Z, Jiang Y, Kottler ML, Brown EM \& Garabédian M. Activating mutations of the calcium-sensing receptor: management of hypocalcemia. Journal of Clinical Endocrinology and Metabolism 200186 5313-5323. (doi:10.1210/jcem.86.11.8016)

96 Sato K, Hasegawa Y, Nakae J, Nanao K, Takahashi I, Tajima T, Shinohara N \& Fujieda K. Hydrochlorothiazide effectively reduces urinary calcium excretion in two Japanese patients with gainof-function mutations of the calcium-sensing receptor gene. Journal of Clinical Endocrinology and Metabolism 200287 3068-3073. (doi:10.1210/jcem.87.7.8639)

97 Caplan RH \& Beguin EA. Hypercalcemia in a calcitriol-treated hypoparathyroid woman during lactation. Obstetrics and Gynecology $199076485-489$.

98 Sadeghi-Nejad A, Wolfsdorf JI \& Senior B. Hypoparathyroidism and pregnancy. Treatment with calcitriol. Journal of the American Medical Association 1980243 254-255. (doi:10.1001/jama.1980. 03300290036018 )
99 Salle BL, Berthezene F, Glorieux FH, Delvin EE, Berland M, David L, Varenne JP \& Putet G. Hypoparathyroidism during pregnancy: treatment with calcitriol. Journal of Clinical Endocrinology and Metabolism 198152 810-813. (doi:10.1210/jcem-52-4-810)

100 Graham WP III, Gordan GS, Loken HF, Blum A \& Halden A. Effect of pregnancy and of the menstrual cycle on hypoparathyroidism. Journal of Clinical Endocrinology and Metabolism 196424 512-516. (doi:10.1210/jcem-24-6-512)

101 Mather KJ, Chik CL \& Corenblum B. Maintenance of serum calcium by parathyroid hormone-related peptide during lactation in a hypoparathyroid patient. Journal of Clinical Endocrinology and Metabolism 199984 424-427. (doi:10.1210/jcem.84.2.5486)

102 Cundy T, Haining SA, Guilland-Cumming DF, Butler J \& Kanis JA. Remission of hypoparathyroidism during lactation: evidence for a physiological role for prolactin in the regulation of vitamin D metabolism. Clinical Endocrinology 198726 667-674. (doi:10.1111/ j.1365-2265.1987.tb00824.x)

103 Markestad T, Ulstein M, Bassoe HH, Aksnes L \& Aarskog D. Vitamin D metabolism in normal and hypoparathyroid pregnancy and lactation. Case report. British Journal of Obstetrics and Gynaecology 198390 971-976. (doi:10.1111/j.1471-0528.1983.tb06774.x)

104 Rude RK, Haussler MR \& Singer FR. Postpartum resolution of hypocalcemia in a lactating hypoparathyroid patient. Endocrinologia Japonica 198431 227-233. (doi:10.1507/endocrj1954.31.227)

105 Shomali ME \& Ross DS. Hypercalcemia in a woman with hypoparathyroidism associated with increased parathyroid hormone-related protein during lactation. Endocrine Practice 19995 198-200. (doi:10.4158/EP.5.4.198)

106 Wright AD, Joplin GF \& Dixon HG. Post-partum hypercalcaemia in treated hypoparathyroidism. BMJ 19691 23-25. (doi:10.1136/bmj.1. 5635.23)

107 Cusano NE, Rubin MR, McMahon DJ, Zhang C, Ives R, Tulley A, Sliney J Jr, Cremers SC \& Bilezikian JP. Therapy of hypoparathyroidism with PTH(1-84): a prospective four-year investigation of efficacy and safety. Journal of Clinical Endocrinology and Metabolism 201398 137-144. (doi:10.1210/jc.2012-2984)

Received 25 June 2015 Accepted 25 June 2015 